\title{
Identification of Potential Calorie Restriction-Mimicking Yeast Mutants with Increased Mitochondrial Respiratory Chain and Nitric Oxide Levels
}

\author{
Bin Li, ${ }^{1}$ Craig Skinner, ${ }^{1}$ Pablo R. Castello, ${ }^{2}$ Michiko Kato, ${ }^{1}$ Erin Easlon, ${ }^{1}$ Li Xie, ${ }^{1}$ \\ Tianlin Li, ${ }^{1}$ Shu-Ping Lu, ${ }^{1}$ Chen Wang, ${ }^{1}$ Felicia Tsang, ${ }^{1}$ Robert O. Poyton, ${ }^{2}$ and Su-Ju Lin ${ }^{1}$ \\ ${ }^{1}$ Department of Microbiology, College of Biological Sciences, University of California at Davis, Davis, CA 95616, USA \\ ${ }^{2}$ The Department of Molecular, Cellular and Developmental Biology, University of Colorado, Boulder, CO 80309, USA
}

Correspondence should be addressed to Su-Ju Lin, slin@ucdavis.edu

Received 16 October 2010; Accepted 31 January 2011

Academic Editor: Alberto Sanz

Copyright (C) 2011 Bin Li et al. This is an open access article distributed under the Creative Commons Attribution License, which permits unrestricted use, distribution, and reproduction in any medium, provided the original work is properly cited.

Calorie restriction (CR) induces a metabolic shift towards mitochondrial respiration; however, molecular mechanisms underlying CR remain unclear. Recent studies suggest that CR-induced mitochondrial activity is associated with nitric oxide (NO) production. To understand the role of mitochondria in CR, we identify and study Saccharomyces cerevisiae mutants with increased NO levels as potential CR mimics. Analysis of the top 17 mutants demonstrates a correlation between increased NO, mitochondrial respiration, and longevity. Interestingly, treating yeast with NO donors such as GSNO ( $S$-nitrosoglutathione) is sufficient to partially mimic CR to extend lifespan. CR-increased NO is largely dependent on mitochondrial electron transport and cytochrome c oxidase (COX). Although COX normally produces NO under hypoxic conditions, CR-treated yeast cells are able to produce NO under normoxic conditions. Our results suggest that CR may derepress some hypoxic genes for mitochondrial proteins that function to promote the production of $\mathrm{NO}$ and the extension of lifespan.

\section{Introduction}

Calorie restriction (CR) extends lifespan in a variety of organisms and has also been shown to ameliorate many age-associated diseases such as diabetes and cancers [1-3]. However, the molecular mechanisms underlying CR-induced beneficial effects are still not fully understood. Owing to a short lifespan and well-established molecular genetic techniques, the budding yeast Saccharomyces cerevisiae represents a powerful system to identify new components in CR signaling pathways and to study these factors at the molecular/genetic level. Yeast lifespan can be studied in two distinct ways: replicative lifespan (RLS) and chronological lifespan (CLS). RLS measures the number of cell divisions an individual yeast cell undergoes before senescence (division potential), whereas CLS measures the length of time cells remain viable at a nondividing state (postmitotic survival). RLS may serve as a model to understand the mechanisms of replicative senescence such as in stem cells, while CLS may be more relevant to postmitotic cell senescence in adult animals $[4,5]$.

Moderate CR can be imposed in yeast by reducing the glucose concentration from $2 \%$ to $0.5 \%$ in rich media [6-9], which extends both RLS and CLS. In yeast, CR is suggested to function through reducing the activities of conserved nutrient-sensing pathways. Decreasing the activities of the Ras-cAMP/PKA (cyclic AMP-activated protein kinase A) pathway, Sch9 (homolog of mammalian S6K kinases) and Tor1 kinases have been shown to mimic CR and extend lifespan $[6,10,11]$. The recent identification of additional CR-specific longevity genes provides further insight into the molecular mechanisms underlying $\mathrm{CR}$ and the resulting metabolic alterations [7, 12-17]. The Sir2 family proteins (sirtuins) are among identified CR downstream targets; they are conserved longevity factors that were originally discovered and studied in yeast [3]. Sirtuins are $\mathrm{NAD}^{+}$-dependent 
protein deacetylases that are responsive to metabolic changes and stress and have been shown to play important roles in several CR models [3, 18, 19].

Mitochondria have also been shown to play important roles in $\mathrm{CR}$. In yeast, $\mathrm{CR}$ induces a shunting of carbon metabolism from fermentation to the mitochondrial TCA cycle [12]. This metabolic shift to respiration is necessary and sufficient for the activation of Sir2-mediated lifespan extension in certain yeast strains [12]. A link between CR and increased mitochondrial metabolism has also been reported in higher eukaryotes including mammals [13, 14, 20-22]. Notably, the age-dependent decline in expression of genes encoding components of the mitochondrial respiratory chain has been reported in several species [22-24]. Since mitochondria are the major sites of energy production in eukaryotic cells, these findings highlight the crucial role of energy metabolism in CR. Since CR regimens involve the reduction of nutrient input, it is believed that a global change in nutrient sensing and regulatory pathways as well as changes in the mitochondrial respiratory chain are translated to physiological responses to counteract age-induced effects [25-27].

The role of the mitochondrial respiratory chain in CR is still unclear. In yeast, it has been suggested that CR activates mitochondrial respiration to prevent the accumulation of toxic metabolites [28-30]. Although the mitochondrial electron transport chain is also the primary site for reactive oxygen species (ROS) generation in the eukaryotic cell, increased mitochondrial electron flow during $\mathrm{CR}$ would be expected to reduce ROS levels [3, 31-33]. Recently, cytochrome c oxidase $(\mathrm{COX})$ of the mitochondrial respiratory chain has been shown to catalyze the reduction of nitrite to nitric oxide (NO) [34]. When considered with the findings that the respiratory chain is involved in $\mathrm{CR}$ and that $\mathrm{NO}$ has been implicated in CR, it is of interest to ask if the NO involved is produced by mitochondrial COX.

In order to begin to elucidate how CR modulates complex genetic and metabolic networks to alter stress resistance, genomic stability, and lifespan, it is essential to uncover additional factors in the CR pathway. Towards this end, we have explored the relationship between NO and CR and have identified new genes in CR.

\section{Materials and Methods}

2.1. Yeast Strains and Media. Yeast strains BY4742 MAT $\alpha$ his $3 \Delta 1$ leu $2 \Delta 0$ lys $2 \Delta 0$ ura $3 \Delta 0$ and the genome-wide gene deletion collections (nonessential genes) were acquired from Open Biosystems. Medium used for replicative lifespan (RLS) analysis was YEP (2\% bacto peptone, $1 \%$ yeast extract, $1.5 \%$ agar) supplemented with filter-sterilized glucose at a final concentration of $2 \%$ or $0.5 \%$. Medium used for chronological lifespan (CLS) analysis was minimal synthetic $\mathrm{SD}(6.7 \mathrm{~g} / \mathrm{L}$ yeast nitrogen base) supplemented with $4 \mathrm{x}$ auxotrophic amino acids (leucine, histine, uracil, and lysine) and glucose to a final concentration of $2 \%$ or $0.5 \%$. Gene deletions were made by replacing the wild-type genes with the reusable $\mathrm{Kan}^{r}$ marker as described in [16] and verified by Polymerase Chain Reaction (PCR) using oligonucleotides flanking the genes of interest.

2.2. GSNO Treatments. Different concentrations of GSNO were added to yeast cells during chronological lifespan assays at different time points. GSNO was made as follow: $200 \mu \mathrm{L}$ of $0.5 \mathrm{M}$ GSH in $0.5 \mathrm{M}$ HCL was added to $200 \mu \mathrm{L}$ of $0.5 \mathrm{M} \mathrm{NaNO}_{2}$ and then incubated at $4^{\circ} \mathrm{C}$ in the dark. After 30 minutes, $400 \mu \mathrm{L}$ of $0.25 \mathrm{M} \mathrm{NaOH}$ was added to neutralize the solution. This reaction generated GSNO at final concentration of $\sim 125 \mathrm{mM}$. Inactivated GSNO was generated by exposing GSNO to UV illumination for $30 \mathrm{~min}$ (photolysis) [35].

2.3. Measurement of Relative NO Levels Using the DAFFM DA Fluorescence Dye. Diaminofluorescein-FM diacetate (Kamiya Biomedical) was diluted to $1 \mu \mathrm{M}$ in reaction buffer (0.2 M phosphate buffer, $\mathrm{pH} 7,1 \mathrm{mM}$ EDTA, $0.1 \%$ glucose) immediately prior to the assay. Cells at different growth stages were harvested, washed twice, and then resuspended into $120 \mu \mathrm{L}$ of reaction buffer $(0.2 \mathrm{M}$ potassium phosphate buffer, pH 7, $1 \mathrm{mM}$ EDTA, $0.1 \%$ glucose). $100 \mu \mathrm{L}$ of cell suspension was added to $100 \mu \mathrm{L}$ reaction buffer with $1 \mu \mathrm{M}$ of DAF-FM DA in 96-well fluorescence assay plates $\left(\sim 5 \times 10^{6}\right.$ cells were analyzed in each well). After 2 hours of incubation $\left(30^{\circ} \mathrm{C}\right)$, fluorescence signals were detected using a plate reader with excitation at $485 \mathrm{~nm}$ and emission monitored at emission at $535 \mathrm{~nm}[36,37]$.

2.4. Nitric Oxide (NO) Measurement by an NO-Specific Electrode in Intact Cells. Cells were grown in YPD media containing either $0.5 \%$ or $2 \%$ glucose on a shaker $(200 \mathrm{rpm})$ at $28^{\circ} \mathrm{C}$ and harvested in mid-exponential phase. Cells were washed twice with cold distilled water, pelleted, and kept on ice until use. Nitrite-dependent NO synthesis was measured essentially as described in [34, 38]. Briefly, cells were resuspended in $2 \mathrm{~mL}$ PBS ( $\mathrm{pH}$ 6.5) in an NO chamber and bubbled $5 \mathrm{~min}$ with nitrogen. Then the chamber was closed, and $\mathrm{NO}$ production was measured at $28^{\circ} \mathrm{C}$ after the addition of $1 \mathrm{mM}$ sodium nitrite using an NO electrode (amiNO-700, Innovative Instrument) as described in [34, 38].

2.5. Polarographic Measurement of $\mathrm{NO}$ Production and $\mathrm{O}_{2}$ Consumption by Mitochondria. Cells were grown as above and harvested in mid-exponential phase. Mitochondria were prepared as described in [39]. NO production was measured with an amino-700 nitric oxide sensor connected to an inNOII nitric oxide measuring system (Innovative Instruments, Inc). Simultaneous measurement of $\mathrm{O}_{2}$ concentration in the chamber was performed by a $2 \mathrm{~mm}$ Clark-type electrode Oxy-2 (Innovative Instruments, Inc) connected to the inNOII. Except where noted, all solutions were nitrite-free. Measurements were performed at $28^{\circ} \mathrm{C}$ in a final reaction volume of $2 \mathrm{~mL}$, in a thermostated chamber with a close-fitting lid containing ports for the electrodes and a Hamilton syringe. Assays for NO production by the mitochondrial respiratory chain were performed in $\mathrm{NO}$ Assay Medium (6 mM succinate, $650 \mathrm{mM}$ mannitol, $10 \mathrm{mM}$ 
$\mathrm{K}_{2} \mathrm{HPO}_{4}$ [pH 6.5], $0.1 \mathrm{mM}$ EDTA, and $10 \mathrm{mM} \mathrm{KCl}$ ). Except where noted, the NO assay medium was prebubbled with air in order to be saturated with oxygen $(200 \mu \mathrm{M})$ prior to addition of $\mathrm{NaNO}_{2}$, which was added to a final concentration of $1 \mathrm{mM}$, and the measurement of $\mathrm{NO}$ production.

2.6. Screens for Genetic Mimics of CR Base on Relative Levels of NO. Each mutant strain from the deletion collection (Open Biosystems) was inoculated into SD in 96-well plates and allowed to grow for 2 days. $4 \mu \mathrm{L}$ saturated culture was then added into $400 \mu \mathrm{L}$ fresh SD and allowed to grow for $12 \mathrm{hr}$. To prepare for NO measurement, cells were spun down in 96-well plates at $3000 \mathrm{RCF}$, washed, and then resuspended into $120 \mu \mathrm{L}$ reaction buffer $(0.2 \mathrm{M}$ phosphate buffer, $\mathrm{pH}$ 7, $1 \mathrm{mM}$ EDTA, $0.1 \%$ glucose). $100 \mu \mathrm{L}$ cell suspension was added to $100 \mu \mathrm{L}$ reaction buffer with $1 \mu \mathrm{M}$ of DAF-FM DA (Kamiya Biomedical) prealiquated in 96-well fluorescence assay plates. Multiple wild-type (WT) controls grown under both normal ( $2 \%$ glucose) and CR $(0.5 \%$ glucose) conditions were included on each 96-well plate as internal controls. Average NO levels of WT controls grown under normal condition (after normalized to cell number) were set to 1 . NO levels of the mutants were normalized to the WT controls on the same plate. We have determined the variations among different plates and different experiments to be $\sim 20 \%$ (data not shown), which was used as the standard deviation for the initial screen.

2.7. Chronological Lifespan (CLS). Three to four single colonies derived from each strain were analyzed in each experiment as described in [4] with a few modifications. Cells were grown in $10 \mathrm{~mL}$ SD (at a starting $\mathrm{OD}_{600}$ of 0.1 ) in $50 \mathrm{~mL}$ tubes on a roller drum set at $250 \mathrm{rpm}$ to ensure proper aerations. Cell viability $\left(\sim 2 \times 10^{8}\right.$ cells were analyzed in each sample) was monitored every 2-3 days by plating a fraction of the culture onto fresh media to determine the colonyforming units (CFU). Cell survival rates were calculated by normalizing the $\mathrm{CFU}$ of each time point to the $\mathrm{CFU}$ of day 0 ( $48 \mathrm{hr}$ after starting CLS, when cells just entered stationary phase). Numbers on the $x$-axes of CLS graphs denote the number of days after entering stationary phase (nonmitotic state). GSNO-treated cells were grown in the dark for the first $24 \mathrm{hr}$.

2.8. Replicative Lifespan (RLS). All RLS analyses were carried out on YEP agar plates supplemented with glucose at a final concentration of $2 \%$ or $0.5 \%$ with 50 cells per strain per experiment [16] using a micromanipulator under a microscope. All RLS assays were repeated at least twice by two different individuals.

2.9. Oxygen Consumption. Oxygen consumption was monitored using a Clark-type electrode as previously described in [16].

2.10. GSNO and NO Metabolizing Activities in Cell Lysates. About $300 \mathrm{OD}_{600}$ units of yeast cells grown to different stages were harvested and homogenized in $1.5 \mathrm{~mL}$ lysis buffer containing $20 \mathrm{mM}$ Tris- $\mathrm{HCl}, \mathrm{pH} 8,0.5 \mathrm{mM}$ EDTA, $0.1 \%$ NP-40, $1 \mathrm{mM}$ phenylmethylsulphonyl fluoride (PMSF) (Sigma), and protease inhibitor tablet (Roche) using a beads beater. The GSNO reductase (GSNOR) activity of Sfal was determined by measuring GSNO-dependent $\mathrm{NADH}$ consumption using fluorescence $(340 / 460 \mathrm{~nm})$ as described in [40] in $200 \mu \mathrm{L}$ reaction buffer $(200 \mu \mathrm{M} \mathrm{NADH}, 20 \mathrm{mM}$ Tris- $\mathrm{HCl}, \mathrm{pH} 8,0.5 \mathrm{mM}$ EDTA) with $15 \mu \mathrm{g}$ (total proteins) cell lysate and 0 or $200 \mu \mathrm{M}$ GSNO at room temperature. The NO metabolizing activity of Yhbl was determined by measuring NO-dependent $\mathrm{NADH}$ consumption using fluorescence $(340 / 460 \mathrm{~nm})$ as described in [41] in a $200 \mu \mathrm{L}$ reaction mix containing $200 \mu \mathrm{M} \mathrm{NADH}, 20 \mathrm{mM}$ Tris- $\mathrm{HCl}$, pH $8,0.5 \mathrm{mM}$ EDTA, $15 \mu \mathrm{g}$ lysate, and 0 or $300 \mu \mathrm{M}$ MAHMA NONOate (Cayman Chemical) at room temperature. The $\mathrm{NADPH}$-dependent NO-metabolizing activity was measured by MAHMA NONOate-dependent consumption of NADPH using fluorescence $(340 / 460 \mathrm{~nm})$ as described in [42] in a $200 \mu \mathrm{L}$ reaction mix containing $250 \mu \mathrm{M} \mathrm{NADPH}, 20 \mathrm{mM}$ Tris-HCl, pH 8, 0.5 mM EDTA, $15 \mu$ g lysate, and 0 or $300 \mu \mathrm{M}$ MAHMA NONOate at room temperature.

\subsection{CYC7 Reporter Assay. Approximately $1 \mathrm{~kb}$ of the CYC7} promoter was cloned into the URA3+, pYES2.1 vector (Invitrogen) using the BamHI site immediately upstream of the $\beta$-galactosidase gene. For the liquid $\beta$-galactosidase assay, $5 \mathrm{OD}_{600}$ units of yeast cells grown in $\mathrm{SD}$ w/o uracil for $18 \mathrm{hrs}$ (starting $\mathrm{OD}_{600}=0.1$ ) under normoxic condition were washed, lysed by bead beating in breaking buffer $(100 \mathrm{mM}$ Tris-HCl pH 8, 20\% glycerol, $1 \mathrm{mM}$ DTT, $0.02 \%$ SDS, $8 \mathrm{mM}$ PMSF), and separated from debris by centrifugation. $50 \mu \mathrm{L}$ of lysate was then added to $450 \mu \mathrm{L}$ of $\mathrm{Z}$ buffer $(0.1 \mathrm{M}$ sodium phosphate buffer $\mathrm{pH} 7,10 \mathrm{mM} \mathrm{KCl}, 1 \mathrm{mM} \mathrm{MgSO}_{4}, 50 \mathrm{mM} \beta$ mercaptoethanol), preincubated at $30^{\circ} \mathrm{C}$ for $5 \mathrm{~min}$, and then $100 \mu \mathrm{L} 4 \mathrm{mg} / \mathrm{mL}$ ONPG in Z buffer was added. After $1 \mathrm{hr}$ incubation at $30^{\circ} \mathrm{C}$, the reaction was stopped with $250 \mu \mathrm{L}$ of $1 \mathrm{M} \mathrm{NaCO}_{3}$ and read at $420 \mathrm{~nm}$. This reading was then normalized to protein concentration of the lysate and finally normalized to the WT $2 \%$ glucose sample.

2.12. L-NAME Treatment for NO Quantitation. Cells were first inoculated in SD (staring $\mathrm{OD}_{600}=0.1$ ) and allowed to grow for $12 \mathrm{hrs}$. The arginine analogue and NOS inhibitor L-NAME (Sigma) was then added to these cells at $200 \mathrm{mM}$ final concentration as previously described in [43]. After $2 \mathrm{hr}$ incubation at $30^{\circ} \mathrm{C}$, cells were washed and then incubated with the DAF-FM DA fluorescence dye to determine relative NO levels as described previously.

2.13. Hydrogen Peroxide and GSNO Toxicity Tests. For hydrogen peroxide treatments, cells were pregrown in SD with $2 \%$ or $0.5 \%$ glucose $(\mathrm{CR})$ for $20 \mathrm{hrs}$ (staring $\mathrm{OD}_{600}=0.1$ ) then were treated with $0.5 \% \mathrm{H}_{2} \mathrm{O}_{2}$ for $1 \mathrm{hr}$. Following this treatment, cells were plated on YPD in 5-fold serial dilutions. For GSNO toxicity test, cells were pregrown in SD with $2 \%$ or $0.5 \%$ glucose (CR) or pretreated with $25 \mu \mathrm{M}$ GSNO for $18 \mathrm{hr}$. GSNO was then added to cells at a final concentration of $1.5 \mathrm{mM}$. After $24 \mathrm{hr}$ treatment, cells were removed from 
the GSNO-containing SD, plated on YPD in 5-fold serial dilutions, and then allowed to grow for 2 days at $30^{\circ} \mathrm{C}$.

2.14. Statistical Analyses. Statistical analysis of CLS was carried out using the AUC method (area under the curve) $[44,45]$. $P$ values were calculated for each pair of lifespans as shown in Supplemental Table 2 (see Supplementary Material available online at doi: 10.4061/2011/673185). Statistical analysis of RLS was carried out using the JMP statistics software (SAS), and the Wilcoxon rank sums tests $P$ values were calculated for each pair of lifespans as shown in Supplemental Table 3. All other $P$ values were calculated using Student's $t$-test (two-tailed).

\section{Results}

3.1. Calorie Restriction Induces a Significant Increase in NO Production. Moderate CR in yeast results in a metabolic shift from fermentation to mitochondrial respiration [12]. In mice, CR-induced mitochondrial biogenesis was attributed to increased expression of endothelial nitric oxide synthase (eNOS) [20]. To further understand the role of NO in CR, we determined whether CR increased NO levels in yeast using an NO-sensitive dye, diaminofluorescein-FM diacetate (DAF-FM DA). Although DAF-FM DA is fairly specific to NO and NO oxidation products $[36,37]$, we further confirmed that it did not cross-react with other reactive oxygen species (such as superoxide and hydrogen peroxide) in vivo under our assay conditions (Supplemental Figure 1). As shown in Figure 1(a), CR significantly increased NOrelated signals during early growth stages, while cells were actively dividing. The long-lived tor $1 \Delta$ and $h x k 2 \Delta$ mutants $[6,11]$ also showed increased NO signals (Figure 1(b)). In addition, CR, tor $1 \Delta$, and $h x k 2 \Delta$ also conferred resistance towards nitrosative stress (treatments of a physiological NO donor S-nitrosoglutathione, GSNO) (Figure 1(c)). We next determined whether the activities of major NO detoxification enzymes were increased by CR. Yeast flavohemoglobin (Yhb1), which catalyzes the conversion of NO to nitrite or nitrous oxide, and GSNO reductase (GSNOR, Sfa1) are the two major enzymes that protect yeast cells from nitrosative stress $[40,41,46]$. Interestingly, Yhb1 activity determined in the crude cell lysate [41] was increased by CR (Figure 1(d)), whereas Sfal activity [40] was not increased by $\mathrm{CR}$, suggesting that Yhb1 may play an important role in CR. In addition, CR also slightly induced NADPHdependent NO-metabolizing activity (Figure 1(d)), which has been reported in mammalian cells [42]. Together, these results demonstrate that CR-induced increases in $\mathrm{NO}$ are not due to decreased NO degradation.

\subsection{A Genetic Screen for High NO Mutants as Potential} CR Genetic Mimics. To identify additional components in the CR pathway, we screened the yeast deletion collection ( $\sim 500$ strains) for mutants with elevated NO levels similar to CR. About 157 high-NO mutants were identified and ranked by NO levels, growth rate, and resistance to GSNO (Supplemental Table 1). CR increases both replicative and chronological lifespan (RLS and CLS). Therefore, we used these criteria to classify potential "CR genetic mimics." Among the top 15 hits, 5 mutants ( $h x t 17 \Delta$, pkh2 2 , gup1 $\Delta$, hhf $1 \Delta$, and soy $1 \Delta$ ) showed extended CLS and RLS (Table 1). Hxt17 is a high-affinity hexose transporter, which may mimic CR by decreasing the activity of the glucose sensing pathways [6]. Pkh2 is a Ser/Thr protein kinase that activates Sch9 [47], and $p k h 2 \Delta$ is likely to behave similar to $\operatorname{sch} 9 \Delta$, which has been shown to mimic CR [11]. Recently, pkh2 $\Delta$ was identified as an RLS-extending mutant [48], providing further validation for our screen. Gup1 is an ER membranelocalized $\mathrm{O}$-acyltransferase involved in remodeling the fatty acid moiety of the GPI anchor [49]. HHF1 encodes one of two identical histone H4 proteins. Depleting histone H4 has been shown to alter the expression levels of specific yeast genes including many genes that regulate energy homeostasis [50, 51]. Soy1/Aim4 is suggested to participate in mitochondrial genome maintenance [52]; however, its molecular function remains unclear.

We next determined whether these long-lived mutants function in the same pathway as CR to extend lifespan. As expected, CR did not significantly alter CLS (Figures 2(a)2(d)) or RLS (Figures 3(a)-3(d)) of most of these longlived mutants, suggesting that these mutations might be in genes that function in the same (or overlapping) pathway to extend CLS and/or RLS (detailed statistical analysis of CLS and RLS is shown in Supplemental Tables 2 and 3, resp.). Two notable exceptions were observed in our studies: the gup $1 \Delta$ (Figures 2(c) and 3(c)) and the soy $1 \Delta$ (Figure 3(b)) mutants. CR further increased gup1 1 RLS (gup $1 \Delta$ versus gup1 1 , CR; $P=.038)$ and vice versa $(\mathrm{CR}$ versus gup1 $\Delta$, CR; $P=$ .004) (Figure 3(c)), suggesting a positive interaction between gup $1 \Delta$ and CR in RLS extension. In addition, although CR-induced CLS was not further increased by gup $1 \Delta$ (CR versus gup1 $\Delta, \mathrm{CR} ; P=.073$ ), the gup1 $\Delta$ mutant exhibited longer CLS under CR ( gup $1 \Delta$ versus gup $1 \Delta, \mathrm{CR} ; P=.035$ ). Interestingly, CR appeared to decrease soy $1 \Delta$-induced RLS (soy $1 \Delta$ versus soy $1 \Delta, \mathrm{CR} ; P=.008$ ) (Figure 3(b)), suggesting a negative interaction between soy $1 \Delta$ and CR. However, soy $1 \Delta$ did not significantly change CR-induced RLS (CR versus soy $1 \Delta, \mathrm{CR} ; P=.49$ ). A potential positive interaction was also observed between $h h f 1 \Delta$ and CR. CR appeared to extend RLS more significantly when combined with $h h f 1 \Delta$ (CR versus $h h f 1 \Delta, \mathrm{CR} ; P=.001)$. However, CR did not significantly change $h h f 1 \Delta$-induced RLS (Figure $3(\mathrm{~d})$ ) ( $h$ hf1 $1 \Delta$ versus $h h f 1 \Delta, \mathrm{CR} ; P=.19$ ).

3.3. CR-Induced Nitric Oxide Production Is Most Likely Generated by Enhanced Mitochondrial Respiration and the Cytochrome c Oxidase. We next determined whether these long-lived, high-NO mutants displayed an increase in mitochondrial respiration similar to CR cells. As shown in Figure 4(a), all of these mutants showed increased oxygen consumption, demonstrating a correlation between increased mitochondrial respiration and NO production. In addition, a functional electron transport chain was required for CR-induced lifespan. CR failed to extend RLS [7, 12] and CLS (Figure 4(b)) in the respiratory-deficient cyt1 $\Delta$ mutant 

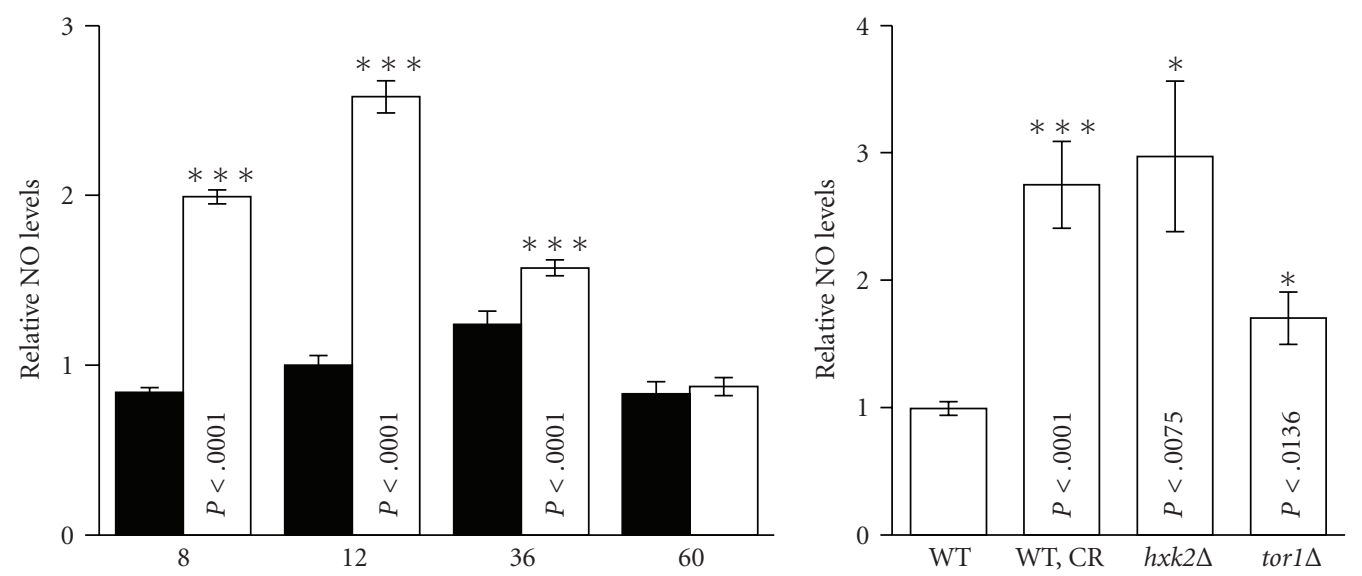

(hr)
- WT
$\square$ WT, CR

(b)

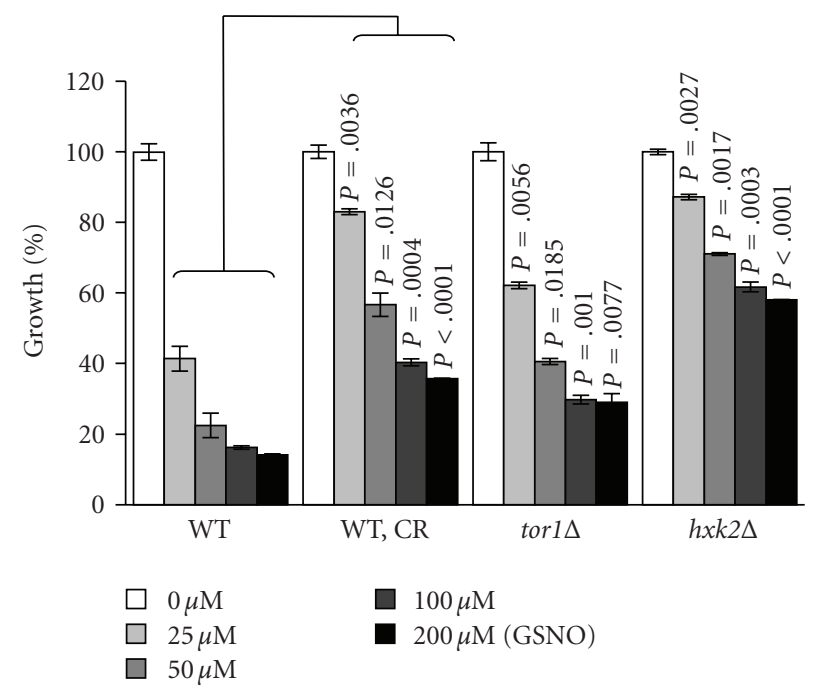

(c)

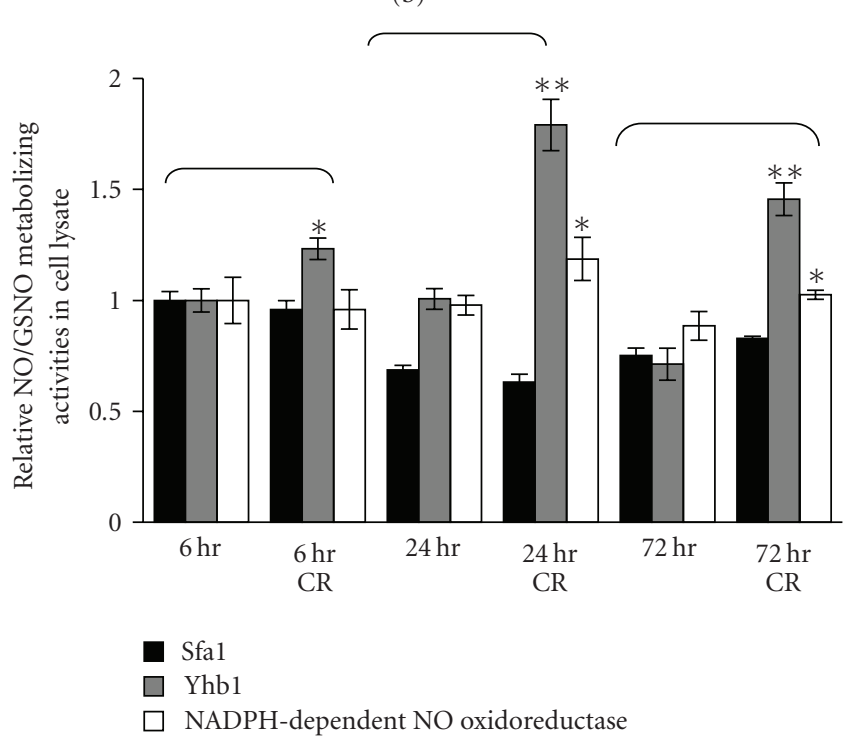

(d)

FIgURE 1: Calorie restriction (CR) and CR genetic mimics increase nitric oxide (NO) levels and confer resistance to nitrosative stress in yeast cell. (a) CR increases NO-related signals during early growth stage. (b) Long-lived tor $1 \Delta$ and $h x k 2 \Delta$ mutants also show increased NOrelated signals. (c) CR and CR mimics confer resistance to $S$-nitrosoglutathione- (GSNO-) induced toxicity. Results show percentages (\%) of growth normalized to no treatment controls after treated with GSNO at indicated concentrations for 20 hr. (d) Yeast cells grown in CR show increased NO metabolizing activities determined in cell lysates. $P$ values are calculated comparing CR cells and the tor $1 \Delta$ or $h x k 2 \Delta$ mutants to WT control. WT: BY4742 wild-type control; CR: $0.5 \%$ glucose; $\Delta$ : gene deletion. One representative set of three independent experiments is shown. Error bars denote standard deviations.

lacking cytochrome c1. Deletion of CYT1 also eliminated the long RLS (Figure 4(c)) and CLS (B. Li and S.-J. Lin, unpublished) of potential CR mimics. We then further examined how CR increased NO production. Although there is biochemical evidence that NOS homologs are present in yeast [43], the existence of nitric oxide synthases in yeast remains controversial since no NOS sequence homolog has been identified. In contrast, cytochrome c oxidase (COX) has been shown to produce $\mathrm{NO}$ in a nitrite- $\left(\mathrm{NO}_{2}{ }^{-}-\right)$dependent manner under hypoxic conditions [34]. Therefore, the mitochondrial electron transport chain is a potential source of NO production in CR cells. Our results (Figure 4(d)) showed that CR- and CR mimics-induced NO increases were largely abolished in cells lacking CYT1. In addition, CR-induced NO production was not inhibited by the NOS inhibitor (arginine analog) L-NAME (Figure 4(e)).

Since the COX complex was reported to produce NO under hypoxic conditions [34], we examined whether calorie-restricted yeast cells could synthesize NO under normal (normoxic) conditions. Using an NO-specific electrode, we verified that calorie-restricted BY4742 WT $\left(\rho^{+}\right)$ cells could produce NO when grown under normoxic 


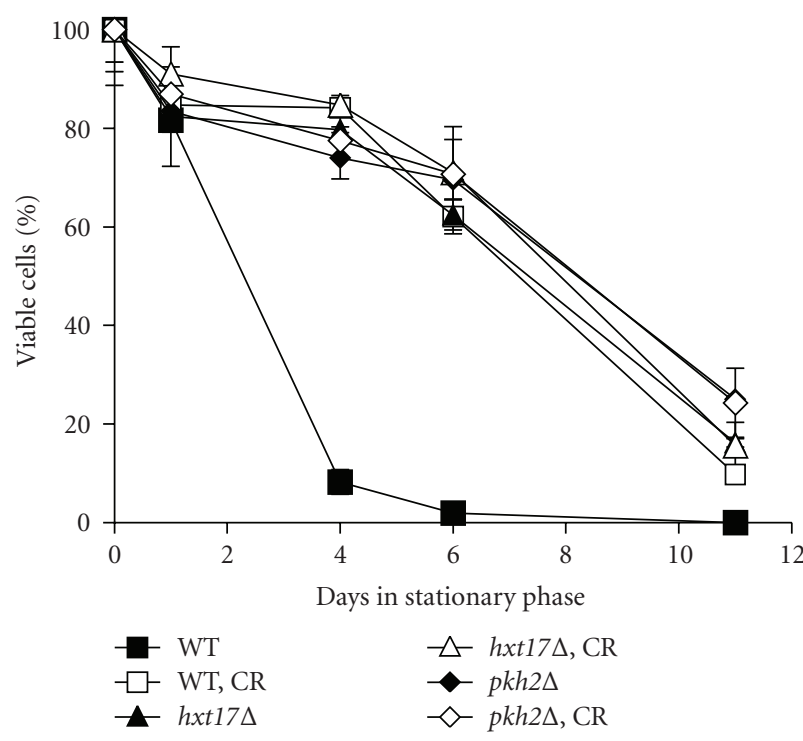

(a)

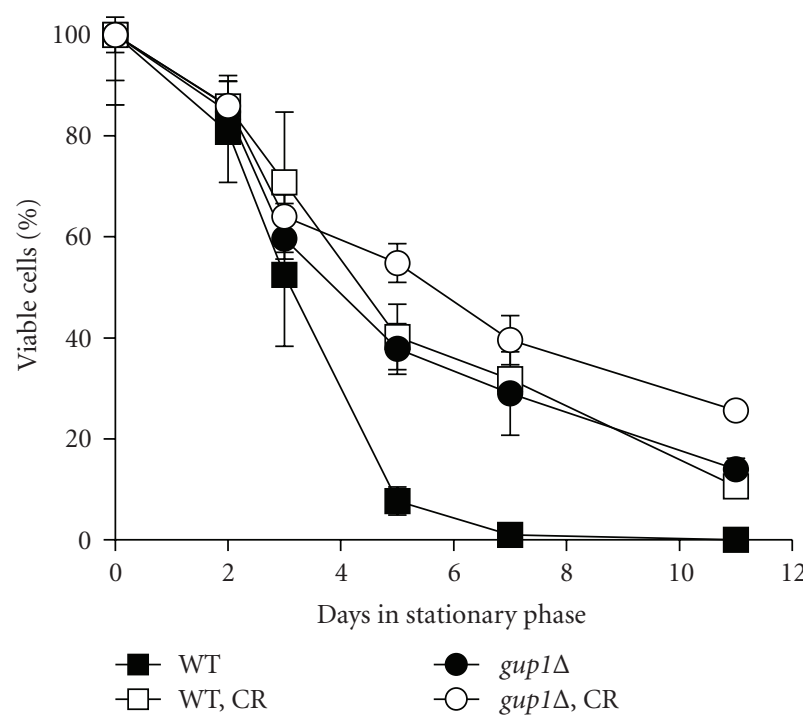

(c)

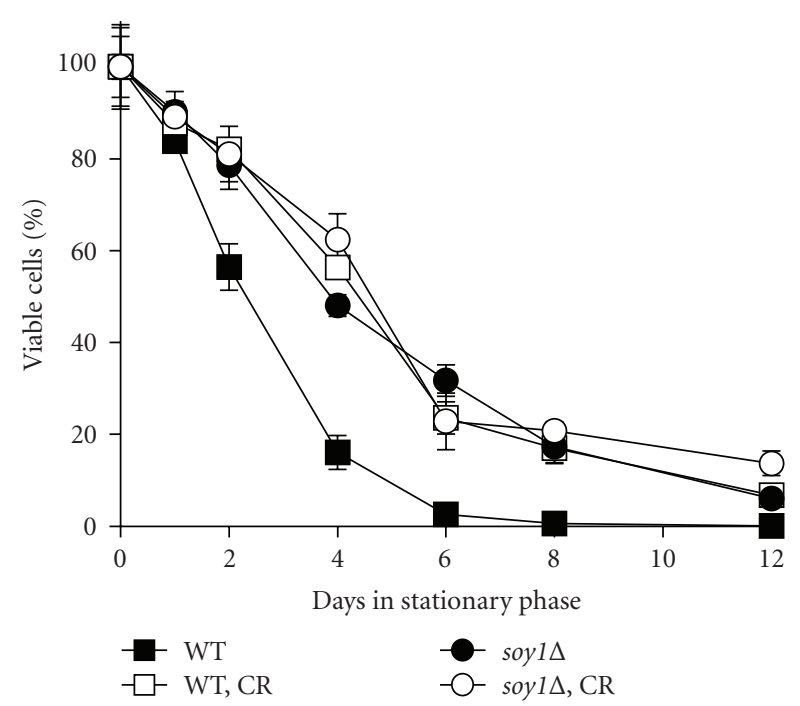

(b)

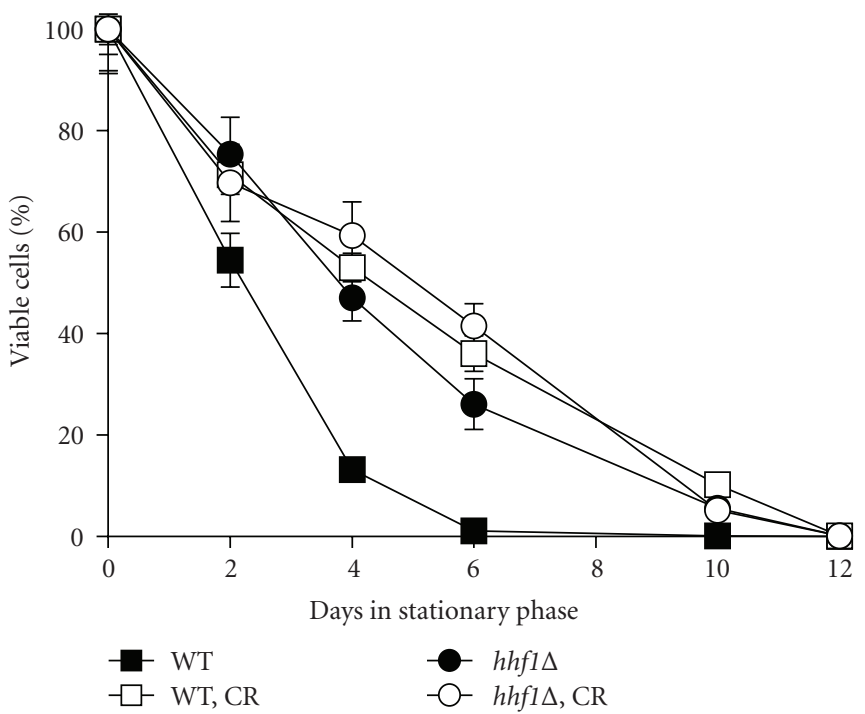

(d)

FIgURE 2: Chronological lifespan (CLS) analysis of potential CR genetic mimics. (a)-(d) Potential CR-mimicking high-NO mutants show extended CLS, and most do not significantly further increase the CLS of cells grown in CR. (c) Although CR further increases gup1 $\Delta$-induced CLS ( gup1 $\Delta$ versus gup1 $\Delta$, CR; $P=.035$ ), gup1 $\Delta$ does not further increase CR-induced CLS (CR versus gup1 1. CR; $P=.073$ ). (d) Although CR further increases $h h f 1 \Delta$-induced CLS ( $h h f 1 \Delta$ versus $h h f 1 \Delta, \mathrm{CR} P=.02$ ), $h h f 1 \Delta$ does not further increase CR-induced CLS (CR versus $h h f 1 \Delta, \mathrm{CR} ; P=.28)$. One representative set of three independent experiments, each conducted in quadruplicate, is shown. Error bars denote standard deviations. WT: BY4742 wild-type control; CR: $0.5 \%$ glucose; $\Delta$ : gene deletion. Numbers on the $x$-axes denote the number of days after entering stationary phase (nonmitotic state). Pairwise statistical analysis of CLS is shown in Supplemental Table 2.

conditions (Figure 4(f)). In contrast, calorie restriction failed to induce NO production either in the BY4742 $\left(\rho^{0}\right)$, a rho ${ }^{0}$ strain lacking mitochondrial DNA, or in the respiratorydeficient cyt1 $\Delta$ mutant under normoxic conditions. These findings further support the conclusion that the NO synthesis in calorie-restricted yeast cells requires a functional mitochondrial respiratory chain. To explore this further, we examined the oxygen sensitivity of nitrite-dependent NO synthesis by mitochondria isolated from WT cells. As shown in Figure 4(g), oxygen sensitivity reported previously for nitrite-dependent mitochondrial NO synthesis [34] was reduced in mitochondria isolated from WT cells grown under CR. These results demonstrated that yeast mitochondria are capable of NO synthesis at oxygen concentrations that are in the normoxic range experienced by yeast cells grown in colonies or in liquid culture.

Eukaryotic cells harbor both aerobic and hypoxic isoforms for several components of the electron transport chain to ensure proper electron transfer in response to different oxygen concentrations [32, 55-57]. It has been reported that, 


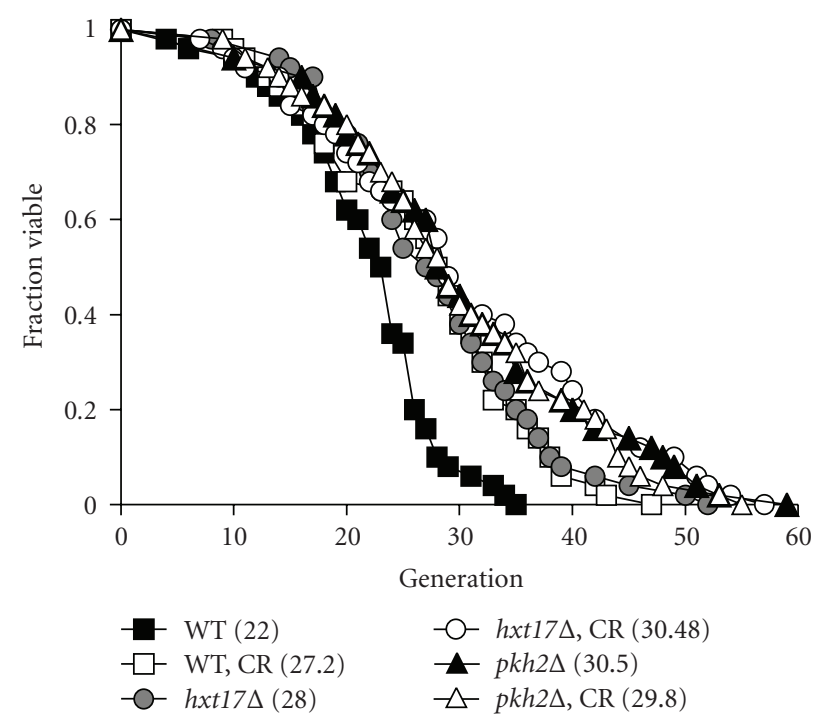

(a)

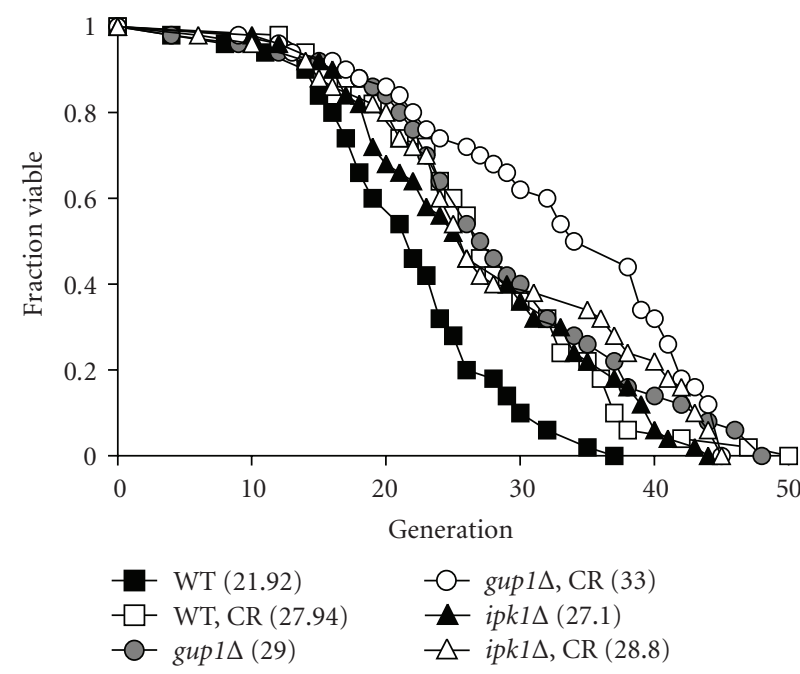

(c)

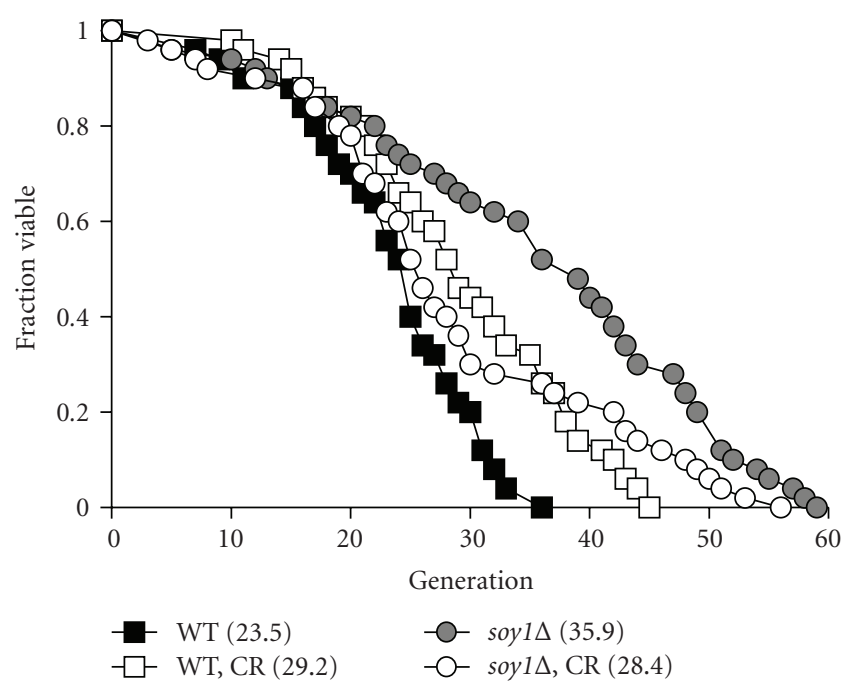

(b)

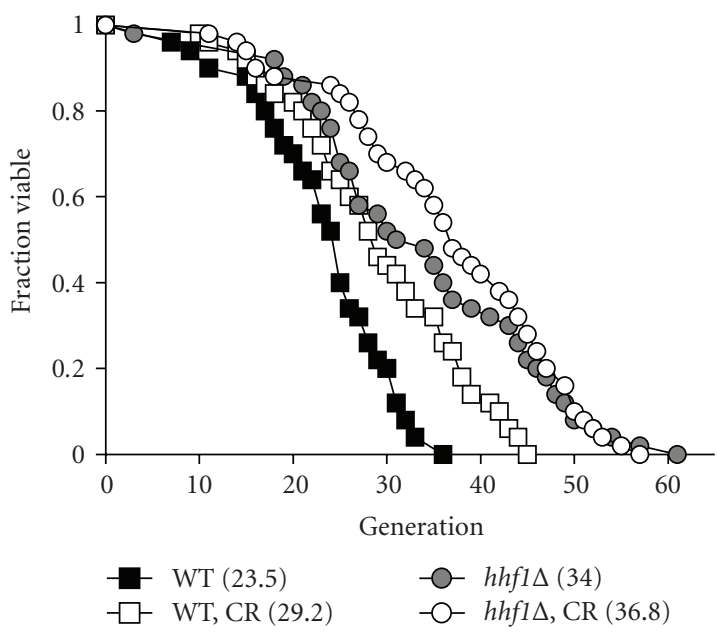

(d)

Figure 3: Replicative lifespan (RLS) analysis of potential CR genetic mimics. (a) Potential CR mimicking high-NO mutants show extended RLS and do not significantly further increase the RLS of cells grown in CR. (b) CR decreases soyl $1 \Delta$-induced RLS (soy1 $\Delta$ versus soy $1 \Delta$, CR; $P=.008$ ); however, soy1 $\Delta$ does not significantly change CR-induced RLS (CR versus soy1 $\Delta, \mathrm{CR} ; P=.49$ ). (c) CR further increases gup1 $1 \Delta$ induced RLS (gup1 $1 \Delta$ versus gup1 $1, \mathrm{CR} P=.038$ ). gup1 $\Delta$ also further increases CR-induced RLS (CR versus gup1 $1 \Delta$, CR; $P=.004)$. (d) Although $h h f 1 \Delta$ further increases CR-induced RLS (CR versus $h h f 1 \Delta, \mathrm{CR} P=.001$ ), CR does not further increase $h h f 1 \Delta$-induced RLS ( $h h f 1 \Delta$ versus $h h f 1 \Delta, \mathrm{CR} P=.19$ ). One representative set of three independent experiments is shown. WT: BY4742 wild-type control; CR: $0.5 \%$ glucose; $\Delta$ : gene deletion. Pairwise statistical analysis of RLS is shown in Supplemental Table 3.

although COX-specific NO synthesis is strongly inhibited by oxygen when COX contains the aerobic isoform of subunit $\mathrm{V}$ (Va), the oxygen inhibition is relieved when COX contains subunit $\mathrm{Vb}$, the hypoxic subunit $\mathrm{V}$ isoform [38]. Interestingly, CR increased the expression of the hypoxia inducible cytochrome c CYC7 (Figure 4(h)) as well as COX5b, which encodes COX hypoxic subunit $\mathrm{Vb}$ (P. Castello and R. Poyton, unpublished). Therefore, CR might induce NO production in part by derepressing expression of the hypoxic isoforms of mitochondrial electron transport complexes and perhaps additional hypoxia responsive genes.
3.4. NO Detoxification Enzymes Are Partially Required for CR-Induced Lifespan Extension. Next, we examined the roles of NO detoxification enzymes Yhbl and Sfal in CR. CR failed to extend RLS in the sfal $\Delta y h b 1 \Delta$ mutant (Figure 5(a)), indicating that $\mathrm{Yhb} 1$ and $S f a 1$ are required for optimal NO homeostasis during CR-induced RLS. Deleting YHB1 partially abolished CR-induced RLS $(P=.03$, CR versus $\mathrm{CR}, y h b 1 \Delta$ ), whereas deleting SFA1 alone had no significant effect. Therefore, it appeared that Yhb1 and Sfa1 play redundant roles under our CR/RLS assay condition. The lifespan of potential CR mimics $h x t 17 \Delta$, pkh2 2 , and 


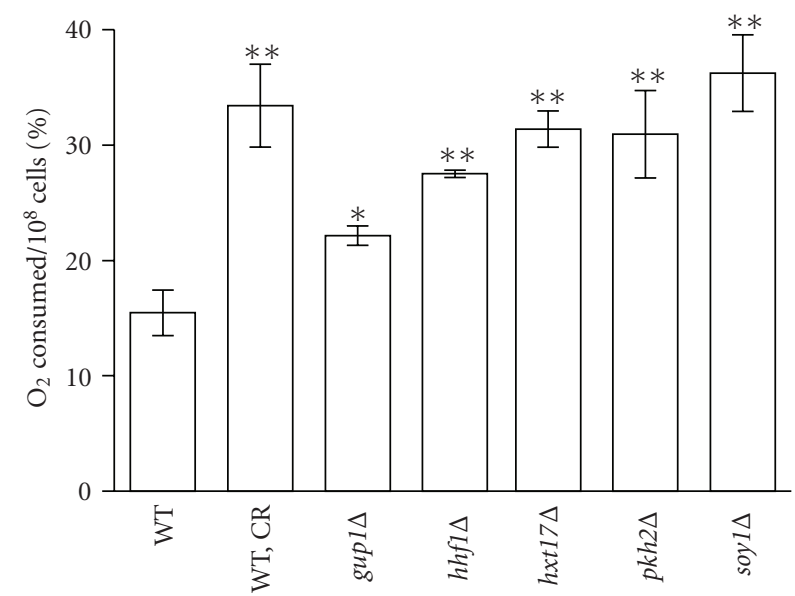

(a)
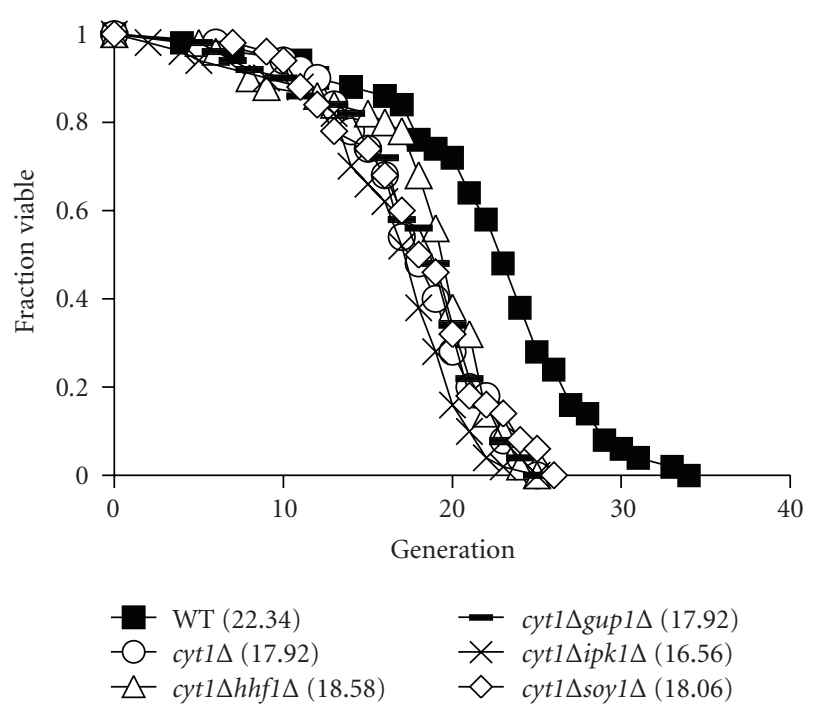

(c)

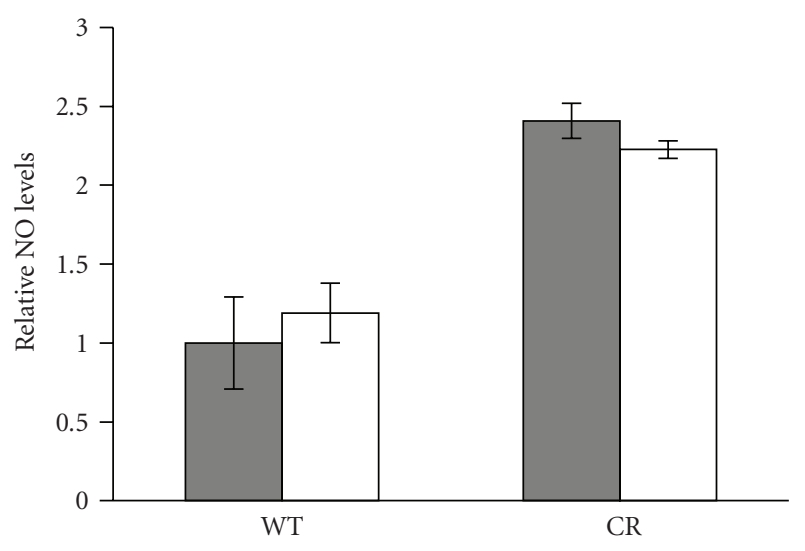

Control

$\square$ L-NAME

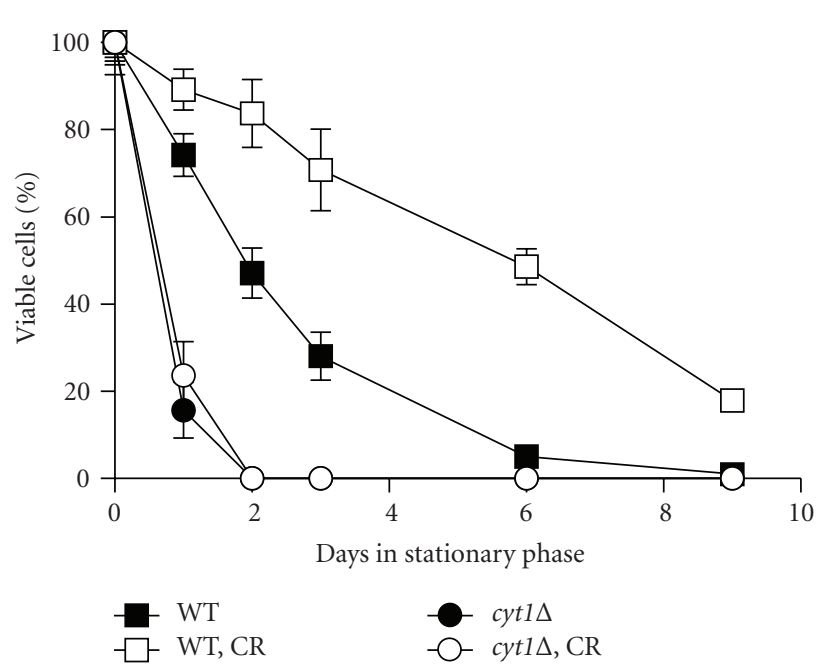

(b)

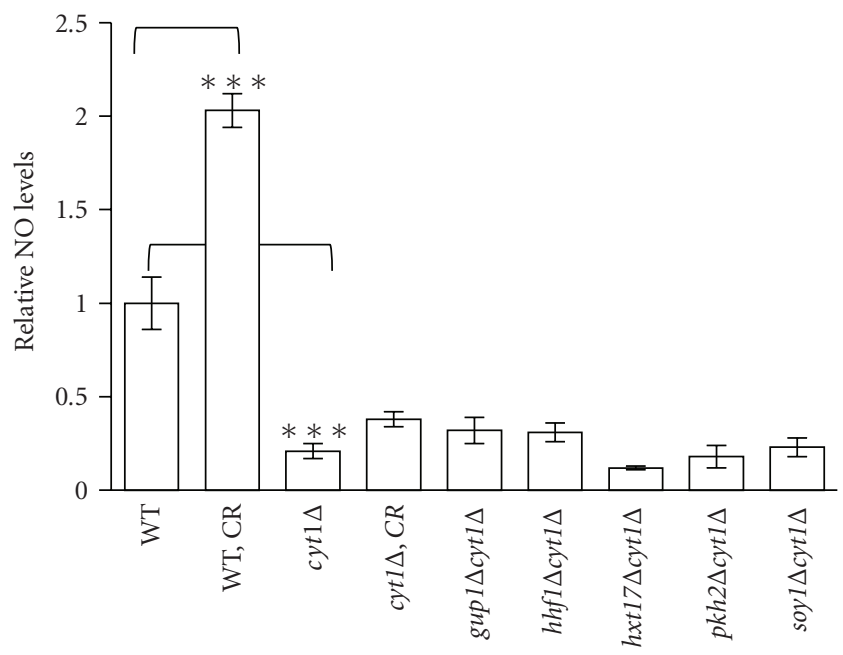

(d)

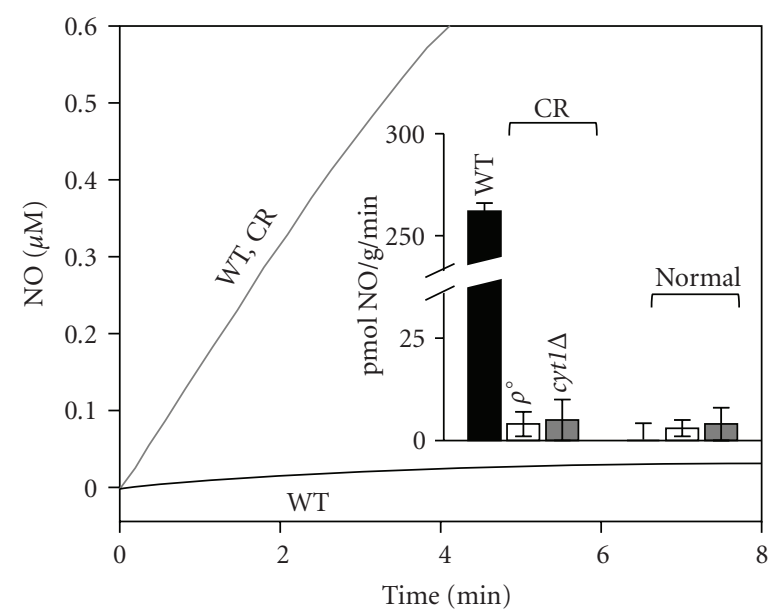

(e)

FIgUre 4: Continued. 


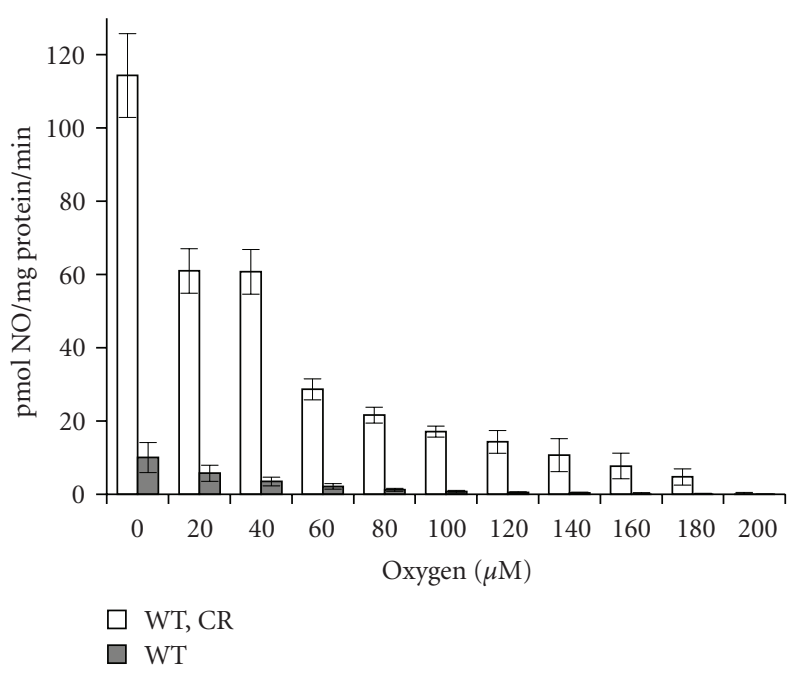

$(\mathrm{g})$

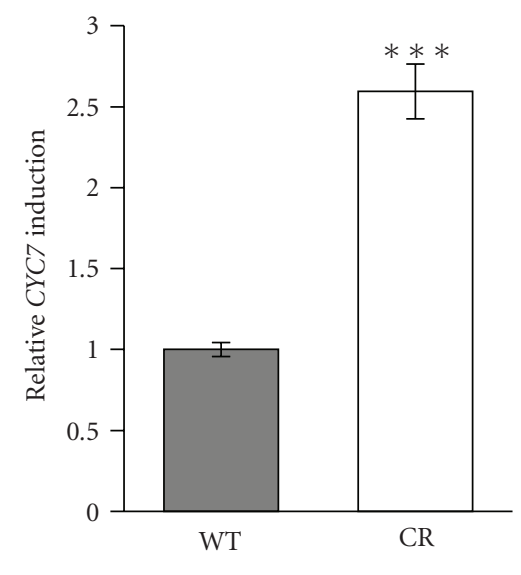

(h)

FIGURE 4: Mitochondrial respiration and NO production play important roles in CR-induced lifespan. (a) All potential CR mimic mutants show increased oxygen consumption. (b) CR-induced CLS is prevented in the cyt1 $\Delta$ mutant. Numbers on $x$-axes denote the number of days after entering stationary phase (nonmitotic state). (c) CR mimic mutants-induced RLS is prevented in the cyt1 $\Delta$ mutant. (d) Increases in NO by CR or CR mimic mutants are largely abolished in the cyt1 $\Delta$ mutant. (e) CR-induced NO production is not inhibited by LNAME, an NOS inhibitor. (f) Involvement of the respiratory chain in cellular NO production. Cells (160 mg) were suspended in $2 \mathrm{~mL}$ of PBS and prebubbled for $5 \mathrm{~min}$ with $\mathrm{N}_{2}$ to create anoxic conditions. After 5 min of prebubbling, $\mathrm{NaNO}_{2}$ was added to a final concentration of $1 \mathrm{mM}$, and NO production was measured with an NO polarographic electrode. Insert: NO production rates for BY4742 $\rho^{+}$(black), BY4742 $\rho^{0}$ (white), and cyt1 (grey) for cells that were grown to log phase in $2 \%$ glucose (normal) or $0.5 \%$ glucose (CR). (g) Effects of oxygen concentrations on mitochondrial NO production. Isolated mitochondria from cells grown under normal and CR conditions were assayed for NO production in assay medium as described in the Materials and Methods Section. (h) CR increases CYC7 gene expression using a $\beta$-galactosidase reporter-based promoter activity assay. Original values: $39 \pm 2 \mathrm{nmoles}$ ONPG converted/min/mg protein for WT; $105 \pm 4$ nmoles ONPG converted/min/mg protein for CR. WT: BY4742 and BY4742 $\left(\rho^{+}\right)$wild-type control; $\rho^{0}$ : cells lacking mitochondrial DNA; CR: $0.5 \%$ glucose. One representative set of experiment is shown. Error bars denote standard deviations. $P$ values are calculated using Student's $t$-test $\left({ }^{*} P<.05\right.$; $\left.{ }^{* *} P<.01 ;{ }^{* * *} P<.005\right)$.

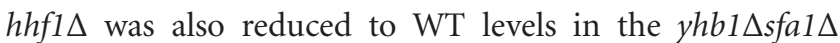
mutant (Figure 5(b)). Deleting YHB1/SFA1 was not likely to prevent CR-induced RLS solely by reducing mitochondrial activity. As shown in Figure 5(c), CR-induced increases in oxygen consumption and $\mathrm{NO}$ production were only partially reduced in the $y h b 1 \Delta s f a 1 \Delta$ mutant. Interestingly, yhb1 $\Delta$ sfa1 $\Delta$ did not abolish CR-induced CLS (Figure 5(d)), suggesting that additional NO-detoxification enzymes and stress response factors might compensate for the loss of Yhb1/Sfal for CR-induced CLS. In line with our results, it has been reported that the stress response factors such as Rim15 and superoxide dismutases play important roles in CR-induced CLS $[9,58]$.

3.5. Treatment with GSNO Extends Yeast CLS. We then examined whether treating cells with NO donors was sufficient to mimic CR to extend lifespan. Interestingly, GSNO appeared to be the most effective NO donor for lifespan extension among the different NO donors tested (B. Li and S.-J. Lin, unpublished). As shown in Figures 6(a) and 6(b), both a single treatment of $25 \mu \mathrm{M} \mathrm{S}$-nitrosoglutathione (GSNO) (which caused mild growth inhibition, Figure 1(c)) and multiple treatments of $5 \mu \mathrm{M}$ GSNO (no growth inhibition observed) extended CLS to a level similar to CR. GSNO did not further increase CR-induced (Figures 6(a) and 6(b)) or CR mimics-induced (Figure 6(c)) CLS suggesting that GSNO and CR may function in the same pathway to extend CLS. Interestingly, GSNO treatments partially rescued the short CLS of the respiratory-deficient cyt $1 \Delta$ mutant (Figure 6(d)), suggesting that it may partially compensate for the loss of respiration or may also confer some respirationindependent beneficial effects. For example, GSNO may extend lifespan by promoting specific protein modifications [59]. However, GSNO treatment $(25 \mu \mathrm{M})$ did not appear to have an impact upon RLS (B. Li and S.-J. Lin, unpublished); this could be an effect of GSNO instability in the platebased RLS assay. It is also likely that GSNO only confers partial beneficial effects of CR. Since CR confers resistance to various stresses, we examined whether GSNO might mimic CR by increasing stress resistance. As shown in Figure 6(e), cells pretreated with a low dose of GSNO were more resistant to GSNO-induced toxicity. Pretreatment of GSNO also slightly increased the resistance to hydrogen peroxide compared to calorie-restricted cells (Figure 6(f)). Therefore, GSNO may extend CLS in part by increasing stress responses, 
TABLE 1: List of potential genetic mimics of CR.

\begin{tabular}{|c|c|c|c|c|c|}
\hline Deletion & $\mathrm{NO}^{\mathrm{a}}$ & $\mathrm{CLS}^{\mathrm{b}}$ & $\mathrm{RLS}^{\mathrm{c}}$ & $\mathrm{O}_{2}{ }^{\mathrm{d}}$ & Biological function \\
\hline$y p k 1 \Delta$ & $4.1 \pm 1.4$ & $\mathrm{E}(0.006)$ & $\mathrm{N}\left(21.5^{\mathrm{wt}} ; 23.2^{\mathrm{mt}} ; 0.15\right)$ & $0.8 \pm 0.03$ & Ser/Thr protein kinase; sphingolipid signaling \\
\hline $\operatorname{tps} 1 \Delta$ & $3.9 \pm 0.9$ & $\mathrm{~N}(0.18)$ & $\mathrm{N}\left(22^{\mathrm{wt}} ; 21.4^{\mathrm{mt}} ; 0.65\right)$ & $1.1 \pm 0.04$ & Trehalose biosynthesis; response to stress \\
\hline reg1 $1 \Delta$ & $2.9 \pm 0.4$ & $\mathrm{E}^{\mathrm{e}}$ & $\mathrm{S}\left(21.5^{\mathrm{wt}} ; 17.6^{\mathrm{mt}} ; 0.0014\right)$ & $1.2 \pm 0.1$ & $\begin{array}{l}\text { Negative regulation of glucose-repressible } \\
\text { genes }\end{array}$ \\
\hline soy $1 \Delta$ & $2.9 \pm 0.4$ & $\mathrm{E}(0.0024)$ & $\mathrm{E}\left(23.5^{\mathrm{wt}} ; 35.9^{\mathrm{mt}} ; 0.0001\right)$ & $2.4 \pm 0.2$ & $\begin{array}{l}\text { Function unknown; associates with nuclear } \\
\text { pore complex }\end{array}$ \\
\hline$h x k 2 \Delta$ & $2.5 \pm 0.8$ & $\mathrm{~N}^{\mathrm{f}}$ & $E^{g}$ & $\sim 3^{\text {h }}$ & Hexokinase; glycolysis \\
\hline $\operatorname{erg} 4 \Delta$ & $2.1 \pm 0.3$ & $\mathrm{E}(0.005)$ & $\mathrm{N}\left(21.5^{\mathrm{wt}} ; 23.9^{\mathrm{mt}} ; 0.54\right)$ & $1 \pm 0.03$ & Ergosterol biosynthesis \\
\hline fyv5 $\Delta$ & $1.8 \pm 0.5$ & $\mathrm{E}(0.004)$ & $\mathrm{N}\left(22.3^{\mathrm{wt}} ; 21.9^{\mathrm{mt}} ; 0.25\right)$ & $1.5 \pm 0.02$ & Ion homeostasis \\
\hline$i p k 1 \Delta$ & $1.8 \pm 0.7$ & $\mathrm{~N}(0.07)$ & $\mathrm{E}\left(21.9^{\mathrm{wt}} ; 27.1^{\mathrm{mt}} ; 0.0065\right)$ & $2.3 \pm 0.2$ & Inositol phosphate biosynthesis \\
\hline$g u p 1 \Delta$ & $1.7 \pm 0.1$ & $\mathrm{E}(0.026)$ & $\mathrm{E}\left(21.9^{\mathrm{wt}} ; 29^{\mathrm{mt}} ; 0.0001\right)$ & $1.4 \pm 0.05$ & $\begin{array}{l}\text { Remodeling the GPI anchors; glycerol } \\
\text { transport }\end{array}$ \\
\hline $\operatorname{lip} 5 \Delta$ & $1.7 \pm 0.3$ & $\mathrm{~N}(0.86)$ & $\mathrm{E}\left(22.5^{\mathrm{wt}} ; 28.4^{\mathrm{mt}} ; 0.01\right)$ & $0.7 \pm 0.05$ & Biosynthesis of lipoic acid \\
\hline$h h f 1 \Delta$ & $1.7 \pm 0.4$ & $\mathrm{E}(0.005)$ & $\mathrm{E}\left(21.3^{\mathrm{wt}} ; 27.7^{\mathrm{mt}} ; 0.0001\right)$ & $1.8 \pm 0.02$ & Histone $\mathrm{H} 4$ proteins; chromatin assembly \\
\hline$d s e 2 \Delta$ & $1.7 \pm 0.1$ & $\mathrm{E}(0.0005)$ & $\mathrm{N} / \mathrm{A}^{\mathrm{i}}$ & $1.6 \pm 0.02$ & Required for cell separation \\
\hline avl9s & $1.6 \pm 0.1$ & $\mathrm{~N}(0.091)$ & $\mathrm{N}\left(23.4^{\mathrm{wt}} ; 26.02^{\mathrm{mt}} ; 0.2\right)$ & $0.9 \pm 0.01$ & $\begin{array}{l}\text { Conserved protein involved in exocytic } \\
\text { transport }\end{array}$ \\
\hline utr1 $1 \Delta$ & $1.6 \pm 0.2$ & $\mathrm{E}(0.001)$ & $\mathrm{N}\left(22.5^{\mathrm{wt}} ; 24.48^{\mathrm{mt}} ; 0.52\right)$ & $1 \pm 0.07$ & Cytosolic NAD kinase \\
\hline$z a p 1 \Delta$ & $1.5 \pm 0.1$ & $\mathrm{E}(0.02)$ & $\mathrm{E}^{\mathrm{j}}\left(22.5^{\mathrm{wt}} ; 29.8^{\mathrm{mt}} ; 0.0124\right)$ & $1.6 \pm 0.1$ & Zinc-regulated transcription factor \\
\hline$p k h 2 \Delta$ & $1.4 \pm 0.2$ & $\mathrm{E}(0.0035)$ & $\mathrm{E}\left(22^{\mathrm{wt}} ; 30.5^{\mathrm{mt}} ; 0.0001\right)$ & $2 \pm 0.25$ & Ser/Thr protein kinase; sphingolipid signaling \\
\hline$h x t 17 \Delta$ & $1.3 \pm 0.1$ & $\mathrm{E}(0.0004)$ & $\mathrm{E}\left(22^{\mathrm{wt}} ; 28^{\mathrm{mt}} ; 0.0014\right)$ & $2 \pm 0.1$ & Hexose transporter \\
\hline
\end{tabular}

This table lists top 15 hits from our screen and the pkh2 $\Delta$ and $h x t 17 \Delta$ mutants. Mutants listed here were first selected by their "growth" (at least 75\% of WT; no severe growth defects) and by "resistance to GSNO" (at least 150\% of WT) and then were ranked by NO levels.

${ }^{a}$ Numbers show average relative intracellular NO levels \pm standard deviation (normalized to wild-type control) (for details, see Section 2). ${ }^{b}$ CLS: chronological lifespan, E: extended; N: normal; $P$ values are calculated using the AUC method (area under the curve) (see Section 2). Results of one set of representative experiment (each conducted in triplicate or quadruplicate, $n=3$ or 4 independent colonies) are shown. About $2 \times 10^{8}$ cells were analyzed in each sample. ${ }^{~}$ RLS: replicative lifespan; E: extended; N: normal; S: short; N/A: not determined. Numbers show (average wild-type RLS; average mutant RLS; $P$ values). $P$ values are calculated using the Wilcoxon rank sums tests. Results of one set of representative experiment are shown. 50 cells $(n=50)$ were analyzed for each strain in each experiment. ${ }^{\mathrm{d}} \mathrm{O}_{2}$ : relative average oxygen consumption rate \pm standard deviation (normalized to wild-type control). ${ }^{\mathrm{e}} \mathrm{Reported}$ [53]. ${ }^{\mathrm{f}}$ Reported [54]. ${ }^{\mathrm{g}}$ Reported [6]. ${ }^{\mathrm{h}}$ Reported [12]. ${ }^{\mathrm{i}} \mathrm{N} / \mathrm{A}$ : not available. Cells are sticky, unable to separate. ${ }^{j}$ Exhibits early cell death.

possibly via inducing hormesis effect. Interestingly, not all of the high-respiration activity CR genetic mimics examined showed increased resistance towards hydrogen peroxide (Figure 6(f)), although these mutants all showed increased resistance towards GSNO (Supplemental Table 1). It is possible that different mutants only partially mimic CR by activating a different subset of stress response pathway. It is also very likely that additional mechanisms play important roles in these mutants.

\section{Discussion}

Calorie restriction (CR) extends longevity and ameliorates age-related diseases in many organisms. Understanding how CR induces these beneficial effects may therefore provide insights into the molecular mechanisms underlying ageassociated diseases. Considerable progress has been made in the discovery of genes/proteins and metabolites that affect longevity. However, many molecular aspects of CRinduced events remain unclear. Uncovering additional longlived CR-mimicking mutants will likely contribute to the understanding of the molecular mechanisms of CR. To identify new components in the CR pathway, we developed a nitric oxide- (NO-) based screen for mutants that showed higher intracellular levels of $\mathrm{NO}$ as potential CR mimics.

Nine of the top 17 high-NO mutants summarized in Table 1 show a positive correlation between increased mitochondrial respiration and NO production. There is also a positive correlation between increased respiration and longevity. These nine mutants showed increased oxygen consumption ( 9 out of 17) and increased CLS and/or RLS. In addition, mutants that showed both extended RLS and CLS (5 out of 17) all showed increased oxygen consumption as well as NO levels (Table 1). Two mutants (avl9s and tps1 $\Delta$ ) that did not show either extended CLS or RLS also did not show increased oxygen consumption. However, it is noteworthy that 5 long-lived mutants (with extended RLS or CLS) did not possess increased oxygen consumption.

Although CR cells have increased NO levels, a higher intracellular NO concentration is not sufficient to extend lifespan under all growth conditions and/or genetic backgrounds. For example, the avl9s and tps $1 \Delta$ mutants have higher NO levels but do not show increased lifespan (Table 1). It is possible that increases in the stress response 

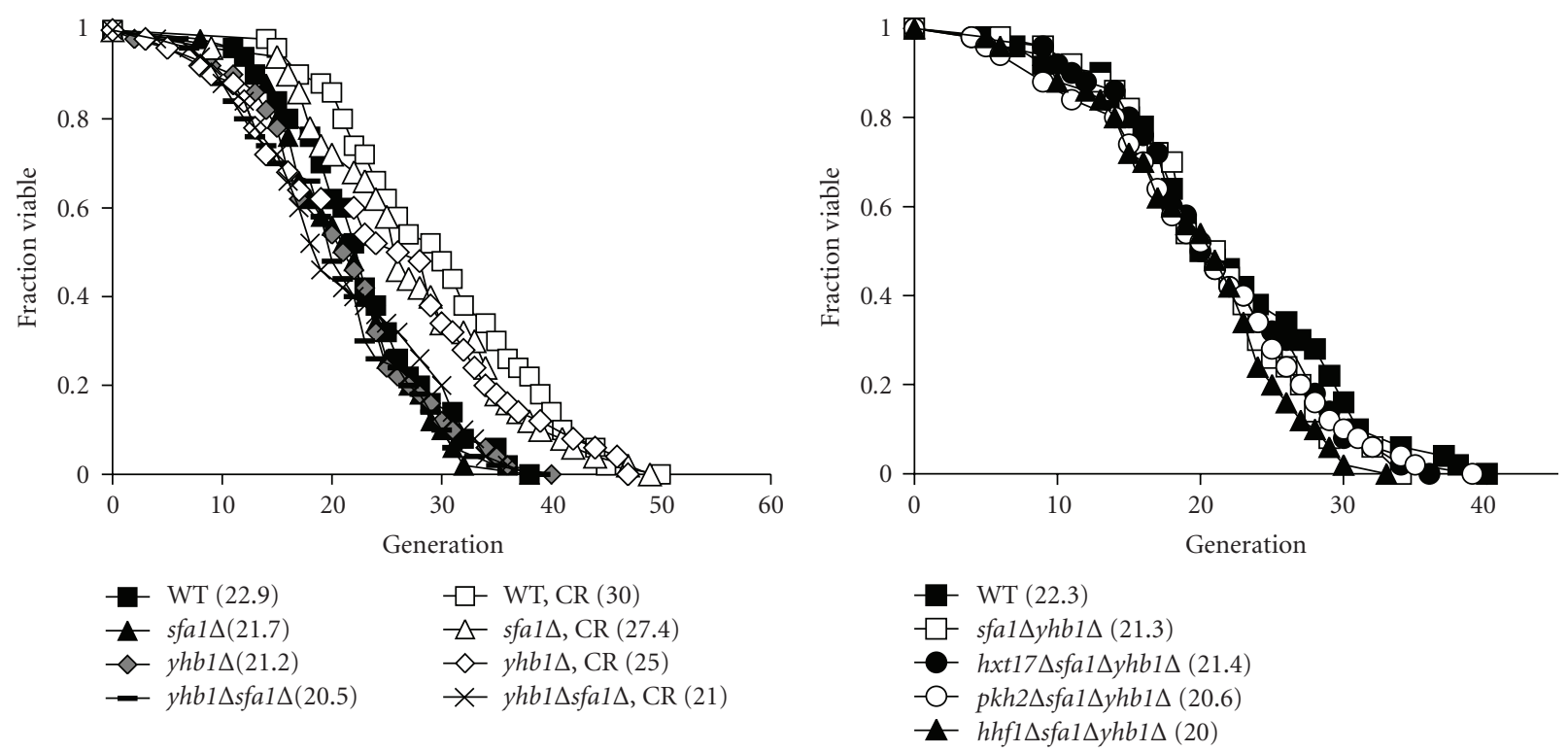

(a)

(b)

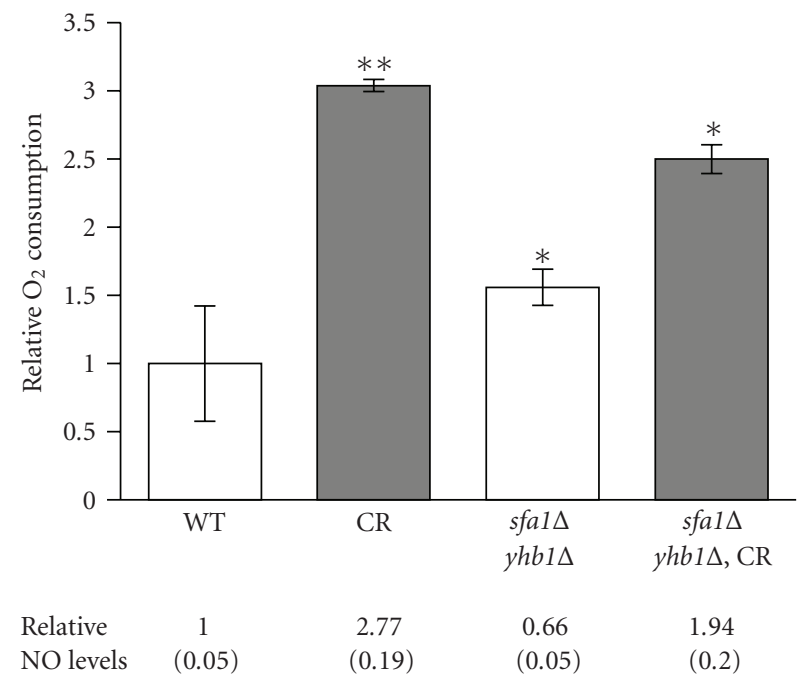

(c)

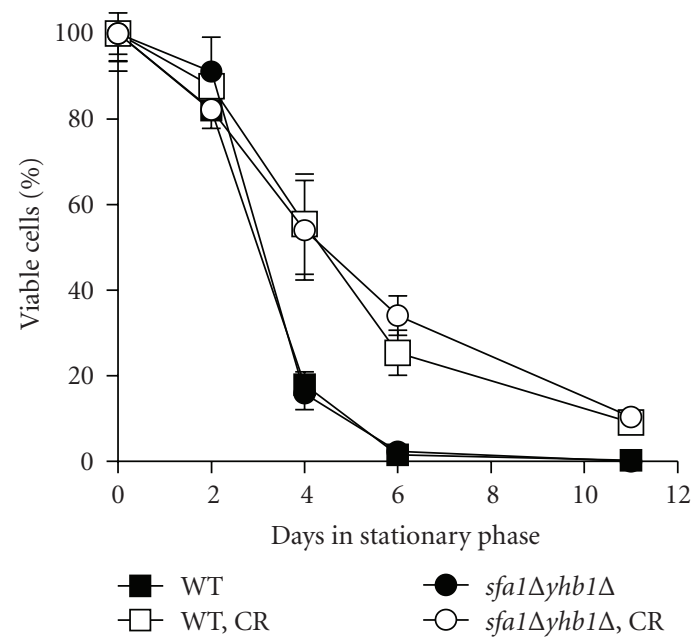

(d)

FIGURE 5: Balanced NO metabolism is required for CR-induced beneficial effects. (a) CR fails to extend RLS in cells lacking Sfa1 and Yhb1. (b) CR genetic mimics fail to extend RLS in cells lacking Sfal and Yhb1. (c) Deleting Sfal and Yhb1 partially affect CR-induced increase in oxygen consumption and NO levels. (d) Sfa1 and Yhb1 are not required for CR-induced CLS. One representative set of experiments is shown. Error bars denote standard deviations. $P$ values are calculated using Student's $t$-test $\left(* P<.05 ; *^{*} P<.01 ;{ }^{* * *} P<.005\right)$.

as well as functional mitochondria are also required for NO-induced lifespan extension. Supporting this model, our results showed that treating the respiratory deficient cyt1 $\Delta$ mutant with GSNO only partially restored its CLS (Figure 6(d)). In addition, it has been shown that several stress response factors play important roles in CLS and CRinduced CLS in S. cerevisiae $[9,33]$. In Schizosaccharomyces pombe, the stress-responsive MAP kinase Sty1 was demonstrated to be essential for CR-mediated CLS extension [60].

NO detoxification enzymes Yhbl and Sfal appear to play an important role in CR-induced RLS (Figure 5(a)) but not CLS (Figure 5(d)). One possible explanation is that perhaps actively dividing cells are more susceptible to CRinduced NO stress. In line with this model, CR increases
NO more significantly in early growth stages during which most cells were still actively dividing (Figure 1(a)). Yhb1 and Sfa1 are dispensable for CR-induced CLS, which may be due to the fact that other NO metabolizing factors and/or stress response factors play more important roles in CRinduced CLS. Interestingly, the $s f a 1 \Delta y h b 1 \Delta$ double mutant (under non-CR conditions) showed decreased NO levels (Figure 5(c)) suggesting that functional NO detoxification is required to support NO production in yeast cells. These results highlight the differences in sensitivity towards NO production and detoxification activities for CR-induced RLS and CLS. It is possible that yeast RLS and CLS have different sensitivities towards certain NO metabolites such as peroxynitrite. Peroxynitrite is formed by the reaction 


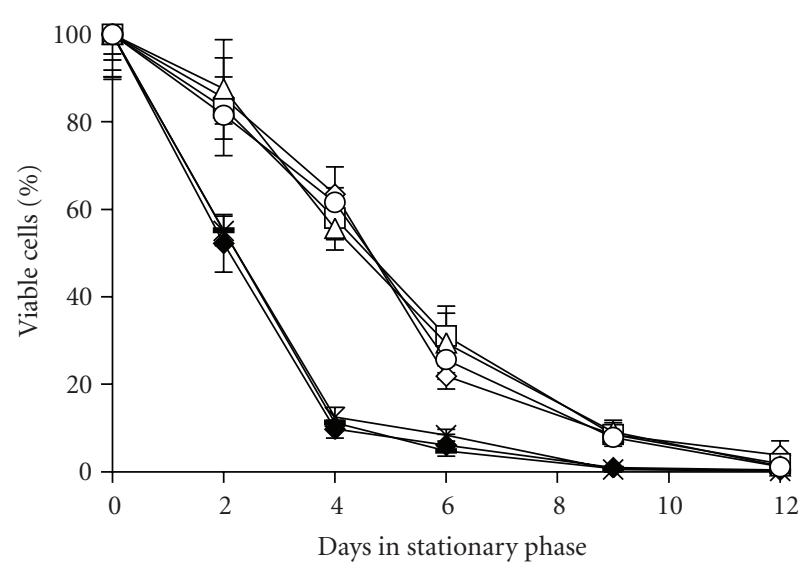

- No treatment control
$\nsucc$ Buffer control
$\multimap$ Inactivated GSNO $(25 \mu \mathrm{M})$
$\prec$ GSNO $(25 \mu \mathrm{M})$

$$
\begin{aligned}
-\square- & \text { CR }+ \text { buffer control } \\
-\circ- & \text { CR }+ \text { GSNO }(25 \mu \mathrm{M}) \\
- & \text { CR }+ \text { inactivated GSNO } \\
& (25 \mu \mathrm{M})
\end{aligned}
$$

(a)

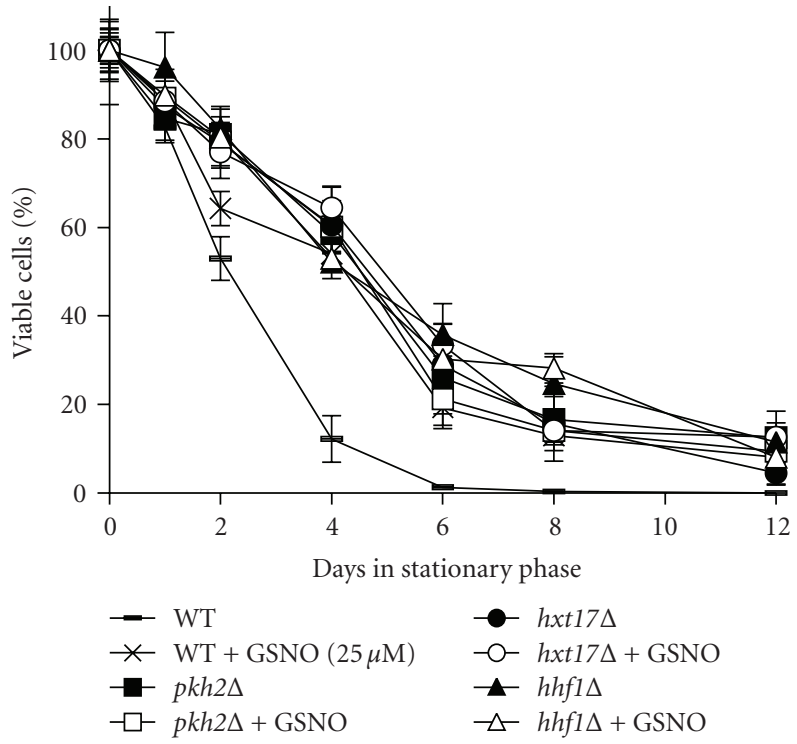

(c)

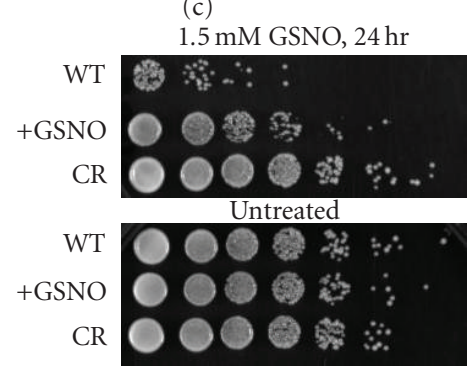

(e)

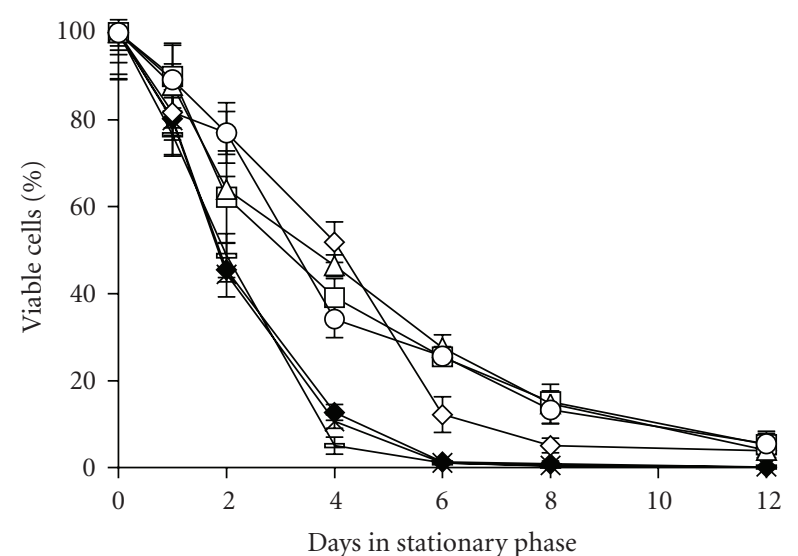

$\begin{array}{ll}- \text { No treatment control } & -\square \text { CR + buffer control } \\ \star \text { Buffer control } & -0-\text { CR }+ \text { GSNO }(5 \mu \mathrm{M}, 6 \mathrm{x}) \\ \multimap-\text { Inactivated GSNO }(5 \mu \mathrm{M}, 6 \mathrm{x}) & -\checkmark \mathrm{CR}+\text { inactivated GSNO }\end{array}$

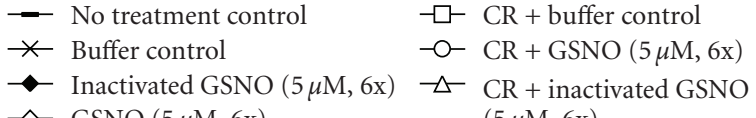
$\prec$ GSNO $(5 \mu \mathrm{M}, 6 \mathrm{x})$

(b)
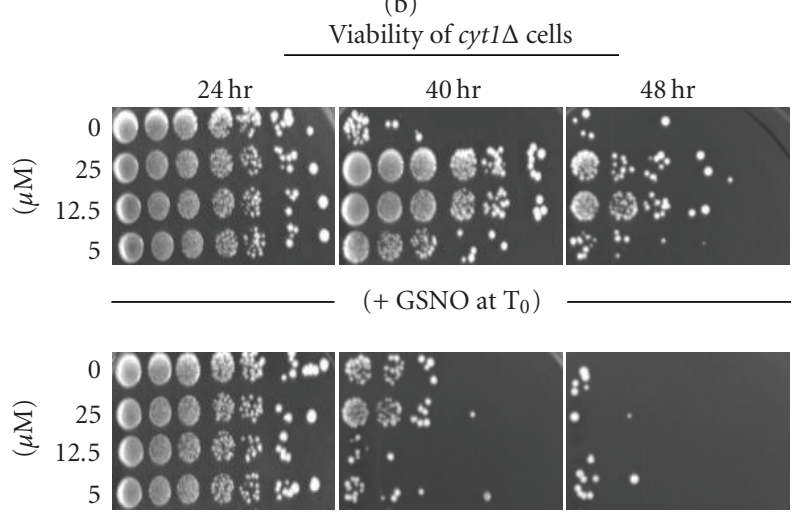

$\left(+\mathrm{GSNO}\right.$ at $\left.\mathrm{T}_{24}\right)$

(d)

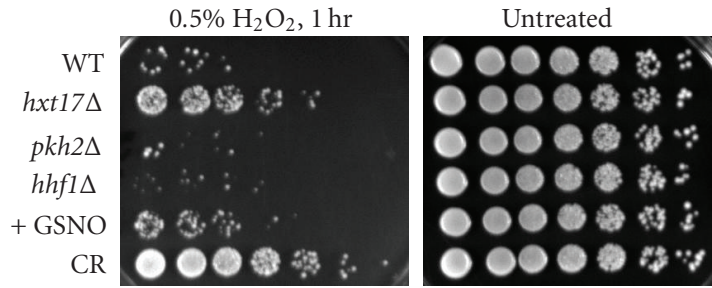

(f)

Figure 6: GSNO treatments extend chronological lifespan (CLS). (a and b) Treating cells with low doses of GSNO extends CLS. (a) Cells are treated with a single dose of GSNO at a final concentration of $25 \mu \mathrm{M}$ upon starting the CLS assay (at 0 hr). (b) Cells are treated with GSNO at a final concentration of $5 \mu \mathrm{M}$ at six different time points (6x): $0,3,6,9,18$, and $24 \mathrm{hr}$. (c) GSNO treatment does not further increase the long CLS of representative CR mimic mutants. (d) GSNO treatments partially rescue the short CLS of the cyt1 $\Delta$ mutant. Results show relative viability of cells taken from GSNO-treated CLS culture (in 5-fold serial dilutions). $\mathrm{T}_{0}$ : treating cells with GSNO upon starting CLS; $\mathrm{T}_{24}$ : treating cells with GSNO $24 \mathrm{hr}$ after starting CLS. (e) Cells pretreated with $25 \mu \mathrm{M}$ GSNO (+GSNO) show resistance towards GSNOinduced toxicity. (f) Cells pretreated with $25 \mu \mathrm{M}$ GSNO (+GSNO) show mild resistance towards hydrogen peroxide-induced toxicity. WT: BY4742 wild-type control; CR: $0.5 \%$ glucose. One representative set of three independent experiments, each conducted in quadruplicate (for $\mathrm{a}, \mathrm{b}$, and c), is shown. Error bars denote standard deviations. For (a) to (c), numbers on $x$-axes denote the number of days after entering stationary phase (nonmitotic state). 


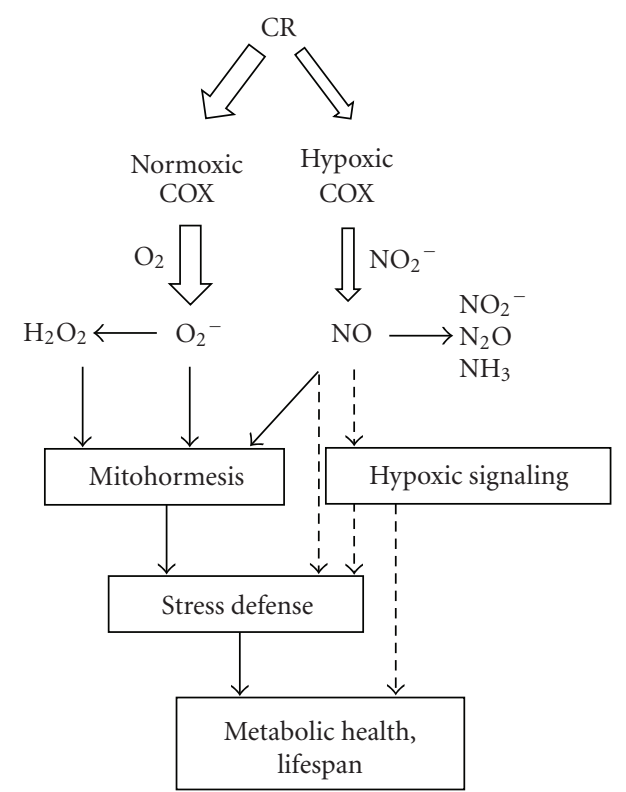

Figure 7: A proposed model for the roles of $\mathrm{NO}$ and mitochondrial respiration in $\mathrm{CR}$. In yeast, the cytochrome $\mathrm{c}$ oxidase (COX) is likely to be responsible for CR-induced NO production. Under normoxic conditions, $\mathrm{CR}$ can activate both oxygen-dependent respiration and nitrite-dependent $\mathrm{NO}$ production, and both require the cytochrome $\mathrm{c}$ oxidase (COX). CR may increase NO production by derepressing expression of the hypoxic isoform subunits of COX and cytochrome c, which are normally repressed by oxygen. ROS detoxification enzymes protect cells from various ROS-associated damages and are required for certain CR-induced beneficial effects. NO and other mitochondrial ROS may induce adaptive gene expression changes as well as a metabolic shift, which optimize metabolism and improve cellular defense system against the oxidative stress that accumulates with age. For clarity and simplicity, many important longevity factors are not shown. Other pathways may work independently or in concert with mitochondrial respiration and stress response to mediate CR.

of NO with superoxide, both of which can be produced by the electron transport chain [32]. It is possible that during replicative aging, superoxide detoxification is not as efficient, making NO scavenging more important. During chronological aging, the high activity of superoxide dismutases can maintain consistently low levels of superoxide, compensating for the lack of NO scavenging. Supporting this possibility, several stress response factors including superoxide dismutase activities have been reported to be upregulated during CLS $[9,33,58]$. In addition, lower levels of superoxide have also been observed in calorie-restricted yeast cells during CLS [58]. Transcription factors associated with respiration (Hap4), stress response (Msn2), and a MAP kinase important in osmoregulation ( $\operatorname{Hog} 1)$ can drive the expression of Yhb1 [61, 62], Sfa1 [63, 64], or both and may regulate increased RLS and resistance to nitrosative stress during CR.

Our results indicate that COX is a major source of $\mathrm{NO}$ production under CR (Figure 7) because deleting components of the electron transport chain in the $r h o^{0}$ (Figure 4(f)), cyt1 $1 \Delta$ (Figures 4(d) and 4(f)), and COX
(B. Li and S.-J. Lin, unpublished) mutants largely abolishes CR-induced NO production and increased longevity (Figures 4(b) and 4(c)). Moreover, GSNO treatments could only partially compensate the loss of respiratory capacity (Figure 6(d)), indicating that both mitochondrial respiration and mitochondrial NO synthesis are required for optimal NO-induced longevity. Interestingly, the hypoxic isoforms of cytochrome $\mathrm{c}$ and $\mathrm{COX}$ subunit $\mathrm{V}$, which are normally repressed by oxygen, are activated by CR (Figure 4(h)) (P. Castello and R. Poyton, unpublished). It is therefore possible that CR activates/de-represses factors that are normally induced by hypoxia to further augment $\mathrm{NO}$ production and respiration capacity. The upregulation of Cox $5 b$ in CR cells could explain both the increased rate of $\mathrm{NO}$ synthesis and the relaxation of oxygen sensitivity because a COX isozyme containing subunit $\mathrm{Vb}$ has been shown to support a higher rate of NO synthesis at high oxygen concentrations [38]. In addition, increased NO has also been suggested to function in the induction of hypoxic genes (hypoxic signaling) [32, $34,65]$. It would be interesting to determine the roles of CR-induced NO production and hypoxic signaling in mitochondrial hormesis (mitohormesis), which also plays an important role increasing stress responses and lifespan [66]. It remains unknown whether COX also plays important roles in CR-induced NO production in mammals, although rat liver mitochondrial COX and human endothelial cell COX also exhibit NO producing activity [34, 65]. In mammals, mitochondrial NO could also come from eNOS, which has been reported to physically interact with the outer mitochondrial membrane [67]. eNOS has been suggested as a mediator of CR in mice, and induction of eNOS caused both mitochondrial biogenesis and enhanced expression of the NAD-dependent protein deacetylase SIRT1 [20]. Together, these studies suggest that NO-mediated signaling and mitochondrial respiration work in concert to adapt cells to metabolic changes induced by $\mathrm{CR}$ leading to enhanced stress response and lifespan extension (Figure 7).

\section{Conclusions}

In summary, we have demonstrated that calorie-restricted yeast cells produce NO under normoxic conditions perhaps by derepressing the hypoxic subunit isoforms of COX and cytochrome c. CR-induced NO production may extend lifespan by increasing the stress response (mitohormesis). Our study may have uncovered potential novel components in the CR pathway and provided tools to analyze the interconnections between $\mathrm{NO}$, mitochondrial respiration, $\mathrm{CR}$, and longevity. Although the CR mimics identified in this study share similar NO levels, lifespan, and oxygen consumption phenotypes with CR, they may activate NO production and regulate mitochondrial respiration and lifespan via different mechanisms. It will be enlightening to examine these differences in future studies. Finally, we propose that CR likely confers its beneficial effects via a mitochondria-NO-mediated adaptive metabolic shift, which optimizes metabolism and at the same time improves cellular defense system against the oxidative stress that accumulates with age. 


\section{Acknowledgments}

The authors thank Dr. Limin Liu, Dr. Moran Benhar, and Dr. Alfred Hausladen for discussions and suggestions on nitric oxide metabolism. They also thank members of the Parales laboratory for assistance with oxygen consumption assays and the screen for high NO mutants and Dr. Xiaowei David Yang for assistance with statistical analysis. This work was supported by grants from National Institute on Aging (AG24351) (to S.-J. Lin), the Ellison Medical Foundation (to S.-J. Lin), and NIH (GM30228) (to R. O. Poyton). B. Li and C. Skinner contributed equally to this work.

\section{Conflict of Interests}

The authors have declared that no conflicts of interest exist.

\section{References}

[1] W. Weindruch and R. L. Walford, The Retardation of Aging and Diseases by Dietary Restriction, Charles C. Thomas, Springfield, Ill, USA, 1998.

[2] G. S. Roth, D. K. Ingram, and M. A. Lane, "Caloric restriction in primates and relevance to humans," Annals of the New York Academy of Sciences, vol. 928, pp. 305-315, 2001.

[3] L. Guarente, "Mitochondria-A Nexus for Aging, Calorie Restriction, and Sirtuins?" Cell, vol. 132, no. 2, pp. 171-176, 2008.

[4] P. Fabrizio and V. D. Longo, "The chronological life span of Saccharomyces cerevisiae," Aging Cell, vol. 2, no. 2, pp. 73-81, 2003.

[5] C. Skinner and S.-J. Lin, "Effects of calorie restriction on life span of microorganisms," Applied Microbiology and Biotechnology, vol. 88, pp. 817-828, 2010.

[6] S. J. Lin, P. A. Defossez, and L. Guarente, "Requirement of NAD and SIR2 for life-span extension by calorie restriction in saccharomyces cerevisiae," Science, vol. 289, no. 5487, pp. 2126-2128, 2000.

[7] E. Easlon, F. Tsang, I. Dilova et al., "The dihydrolipoamide acetyltransferase is a novel metabolic longevity factor and is required for calorie restriction-mediated life span extension," Journal of Biological Chemistry, vol. 282, no. 9, pp. 6161-6171, 2007.

[8] D. L. Smith Jr., J. M. McClure, M. Matecic, and J. S. Smith, "Calorie restriction extends the chronological lifespan of Saccharomyces cerevisiae independently of the Sirtuins," Aging Cell, vol. 6, no. 5, pp. 649-662, 2007.

[9] M. Wei, P. Fabrizio, J. Hu et al., "Life span extension by calorie restriction depends on Rim 15 and transcription factors downstream of Ras/PKA, Tor, and Sch9.," PLoS Genetics, vol. 4, no. 1, article e13, 2008.

[10] P. Fabrizio, F. Pozza, S. D. Pletcher, C. M. Gendron, and V. D. Longo, "Regulation of longevity and stress resistance by Sch9 in yeast," Science, vol. 292, no. 5515, pp. 288-290, 2001.

[11] M. Kaeberlein, R. W. Powers, K. K. Steffen et al., "Cell biology: regulation of yeast replicative life span by TOR and Sch9 response to nutrients," Science, vol. 310, no. 5751, pp. 11931196, 2005.

[12] S. J. Lin, M. Kaeberlein, A. A. Andalis et al., "Calorie restriction extends life span by shifting carbon toward respiration," Nature, vol. 418, pp. 344-348, 2002.
[13] D. Chen, A. D. Steele, S. Lindquist, and L. Guarente, "Medicine: increase in activity during calorie restriction requires Sirt1," Science, vol. 310, no. 5754, p. 1641, 2005.

[14] N. A. Bishop and L. Guarente, "Two neurons mediate dietrestriction-induced longevity in C. elegans," Nature, vol. 447, no. 7144, pp. 545-549, 2007.

[15] S. H. Panowski, S. Wolff, H. Aguilaniu, J. Durieux, and A. Dillin, "PHA-4/Foxa mediates diet-restriction-induced longevity of C. elegans,” Nature, vol. 447, no. 7144, pp. 550555, 2007.

[16] E. Easlon, F. Tsang, C. Skinner, C. Wang, and SU. J. Lin, "The malate-aspartate NADH shuttle components are novel metabolic longevity regulators required for calorie restrictionmediated life span extension in yeast," Genes and Development, vol. 22, no. 7, pp. 931-944, 2008.

[17] K. K. Steffen, V. L. MacKay, E. O. Kerr et al., "Yeast life span extension by depletion of 60 s ribosomal subunits is mediated by Gcn4," Cell, vol. 133, no. 2, pp. 292-302, 2008.

[18] I. Dilova, E. Easlon, and S. J. Lin, "Calorie restriction and the nutrient sensing signaling pathways," Cellular and Molecular Life Sciences, vol. 64, no. 6, pp. 752-767, 2007.

[19] S. I. Imai and L. Guarente, "Ten years of NAD-dependent SIR2 family deacetylases: implications for metabolic diseases," Trends in Pharmacological Sciences, vol. 31, no. 5, pp. 212-220, 2010.

[20] E. Nisoli, C. Tonello, A. Cardile et al., "Cell biology: calorie restriction promotes mitochondrial biogenesis by inducing the expression of eNOS," Science, vol. 310, no. 5746, pp. 314317, 2005.

[21] T. J. Schulz, K. Zarse, A. Voigt, N. Urban, M. Birringer, and M. Ristow, "Glucose restriction extends Caenorhabditis elegans life span by inducing mitochondrial respiration and increasing oxidative stress," Cell Metabolism, vol. 6, no. 4, pp. 280-293, 2007.

[22] K. Zarse, T. J. Schulz, M. Birringer, and M. Ristow, "Impaired respiration is positively correlated with decreased life span in Caenorhabditis elegans models of Friedreich Ataxia," FASEB Journal, vol. 21, no. 4, pp. 1271-1275, 2007.

[23] J. M. Zahn, S. Poosala, A. B. Owen et al., "AGEMAP: a gene expression database for aging in mice," PLoS Genetics, vol. 3, no. 11, article e201, 2007.

[24] J. P. de Magalhães, J. Curado, and G. M. Church, "Metaanalysis of age-related gene expression profiles identifies common signatures of aging," Bioinformatics, vol. 25, no. 7, pp. 875-881, 2009.

[25] S. I. Imai, "SIRT1 and caloric restriction: an insight into possible trade-offs between robustness and frailty," Current Opinion in Clinical Nutrition and Metabolic Care, vol. 12, no. 4, pp. 350-356, 2009.

[26] R. M. Anderson and R. Weindruch, "Metabolic reprogramming, caloric restriction and aging," Trends in Endocrinology and Metabolism, vol. 21, no. 3, pp. 134-141, 2010.

[27] R. H. Houtkooper, R. W. Williams, and J. Auwerx, "Metabolic networks of longevity," Cell, vol. 142, no. 1, pp. 9-14, 2010.

[28] P. Fabrizio, C. Gattazzo, L. Battistella et al., "Sir2 blocks extreme life-span extension," Cell, vol. 123, no. 4, pp. 655-667, 2005.

[29] C. R. Burtner, C. J. Murakami, B. K. Kennedy, and M. Kaeberlein, "A molecular mechanism of chronological aging in yeast," Cell Cycle, vol. 8, no. 8, pp. 1256-1270, 2009.

[30] L. Fontana, L. Partridge, and V. D. Longo, "Extending healthy life span-from yeast to humans," Science, vol. 328, no. 5976, pp. 321-326, 2010. 
[31] M. H. Barros, B. Bandy, E. B. Tahara, and A. J. Kowaltowski, "Higher respiratory activity decreases mitochondrial reactive oxygen release and increases life span in Saccharomyces cerevisiae," Journal of Biological Chemistry, vol. 279, no. 48, pp. 49883-49888, 2004.

[32] R. O. Poyton, K. A. Ball, and P. R. Castello, "Mitochondrial generation of free radicals and hypoxic signaling," Trends in Endocrinology and Metabolism, vol. 20, no. 7, pp. 332-340, 2009.

[33] C. Wang, C. Skinner, E. Easlon, and SU. J. Lin, "Deleting the 14-3-3 protein Bmh1 extends life span in Saccharomyces cerevisiae by increasing stress response," Genetics, vol. 183, no. 4, pp. 1373-1384, 2009.

[34] P. R. Castello, P. S. David, T. McClure, Z. Crook, and R. O. Poyton, "Mitochondrial cytochrome oxidase produces nitric oxide under hypoxic conditions: implications for oxygen sensing and hypoxic signaling in eukaryotes," Cell Metabolism, vol. 3, no. 4, pp. 277-287, 2006.

[35] B. Derakhshan, P. C. Wille, and S. S. Gross, "Unbiased identification of cysteine S-nitrosylation sites on proteins," Nature protocols, vol. 2, no. 7, pp. 1685-1691, 2007.

[36] A. Balcerczyk, M. Soszynski, and G. Bartosz, "On the specificity of 4-amino-5-methylamino-2',7'-difluorofluorescein as a probe for nitric oxide," Free Radical Biology and Medicine, vol. 39, no. 3, pp. 327-335, 2005.

[37] A. Lewinska and G. Bartosz, "Yeast flavohemoglobin protects against nitrosative stress and controls ferric reductase activity," Redox Report, vol. 11, no. 5, pp. 231-239, 2006.

[38] P. R. Castello, K. W. Dong, K. Ball, J. Wojcik, L. Liu, and R. O. Poyton, "Oxygen-regulated isoforms of cytochrome c oxidase have differential effects on its nitric oxide production and on hypoxic signaling," Proceedings of the National Academy of Sciences of the United States of America, vol. 105, no. 24, pp. 8203-8208, 2008.

[39] E. E. McKee and R. O. Poyton, "Mitochondrial gene expression in Saccharomyces cerevisiae. I. Optimal conditions for protein synthesis in isolated mitochondria," Journal of Biological Chemistry, vol. 259, no. 14, pp. 9320-9331, 1984.

[40] L. Liu, A. Hausladen, M. Zeng, L. Que, J. Heitman, and J. S. Stamler, "A metabolic enzyme for S-nitrosothiol conserved from bacteria to humans," Nature, vol. 410, no. 6827, pp. 490494, 2001.

[41] L. Liu, M. Zeng, A. Hausladen, J. Heitman, and J. S. Stamler, "Protection from nitrosative stress by yeast flavohemoglobin," Proceedings of the National Academy of Sciences of the United States of America, vol. 97, no. 9, pp. 4672-4676, 2000.

[42] M. Benhar, M. T. Forrester, D. T. Hess, and J. S. Stamler, "Regulated protein denitrosylation by cytosolic and mitochondrial thioredoxins," Science, vol. 320, no. 5879, pp. 1050-1054, 2008.

[43] B. Almeida, S. Buttner, S. Ohlmeier et al., "NO-mediated apoptosis in yeast," Journal of Cell Science, vol. 120, no. 18, pp. 3279-3288, 2007.

[44] J. C. Pruessner, C. Kirschbaum, G. Meinlschmid, and D. H. Hellhammer, "Two formulas for computation of the area under the curve represent measures of total hormone concentration versus time-dependent change," Psychoneuroendocrinology, vol. 28, no. 7, pp. 916-931, 2003.

[45] D. B. Fekedulegn, M. E. Andrew, C. M. Burchfiel et al., "Area under the curve and other summary indicators of repeated waking cortisol measurements," Psychosomatic Medicine, vol. 69, no. 7, pp. 651-659, 2007.

[46] N. Cassanova, K. M. O’Brien, B. T. Stahl, T. McClure, and R. O. Poyton, "Yeast flavohemoglobin, a nitric oxide oxidoreductase, is located in both the cytosol and the mitochondrial matrix: effects of respiration, anoxia, and the mitochondrial genome on its intracellular level and distribution," Journal of Biological Chemistry, vol. 280, no. 9, pp. 7645-7653, 2005.

[47] R. C. Dickson, "Thematic review series: sphingolipids. New insights into sphingolipid metabolism and function in budding yeast," The Journal of Lipid Research, vol. 49, pp. 909-921, 2008.

[48] E. D. Smith, M. Tsuchiya, L. A. Fox et al., "Quantitative evidence for conserved longevity pathways between divergent eukaryotic species," Genome Research, vol. 18, no. 4, pp. 564570, 2008.

[49] R. Bosson, M. Jaquenoud, and A. Conzelmann, "GUP1 of Saccharomyces cerevisiae encodes an O-acyltransferase involved in remodeling of the GPI anchor," Molecular Biology of the Cell, vol. 17, no. 6, pp. 2636-2645, 2006.

[50] J. J. Wyrick, F. C. P. Holstege, E. G. Jennings et al., "Chromosomal landscape of nucleosome-dependent gene expression and silencing in yeast," Nature, vol. 402, no. 6760, pp. 418-421, 1999.

[51] P. Tongaonkar, S. L. French, M. L. Oakes et al., "Histones are required for transcription of yeast rRNA genes by RNA polymerase I," Proceedings of the National Academy of Sciences of the United States of America, vol. 102, no. 29, pp. 1012910134, 2005.

[52] D. C. Hess, C. Myers, C. Huttenhower et al., "Computationally driven, quantitative experiments discover genes required for mitochondrial biogenesis," PLoS Genetics, vol. 5, no. 3, Article ID e1000407, 2009.

[53] N. D. Bonawitz, M. Chatenay-Lapointe, Y. Pan, and G. S. Shadel, "Reduced TOR signaling extends chronological life span via increased respiration and upregulation of mitochondrial gene expression," Cell Metabolism, vol. 5, no. 4, pp. 265277, 2007.

[54] D. R. Lorenz, C. R. Cantor, and J. J. Collins, "A network biology approach to aging in yeast," Proceedings of the National Academy of Sciences of the United States of America, vol. 106, no. 4, pp. 1145-1150, 2009.

[55] K. E. Kwast, P. V. Burke, K. Brown, and R. O. Poyton, "REO1 and ROX1 are alleles of the same gene which encodes a transcriptional repressor of hypoxic genes in Saccharomyces cerevisiae," Current Genetics, vol. 32, no. 6, pp. 377-383, 1997.

[56] K. E. Kwast, P. V. Burke, B. T. Staahl, and R. O. Poyton, "Oxygen sensing in yeast: evidence for the involvement of the respiratory chain in regulating the transcription of a subset of hypoxic genes," Proceedings of the National Academy of Sciences of the United States of America, vol. 96, no. 10, pp. 5446-5451, 1999.

[57] R. Fukuda, H. Zhang, J. W. Kim, L. Shimoda, C. V. Dang, and G. Semenza, "HIF-1 Regulates Cytochrome Oxidase Subunits to Optimize Efficiency of Respiration in Hypoxic Cells," Cell, vol. 129, no. 1, pp. 111-122, 2007.

[58] A. Mesquita, M. Weinberger, A. Silva et al., "Caloric restriction or catalase inactivation extends yeast chronological lifespan by inducing $\mathrm{H}_{2} \mathrm{O}_{2}$ and superoxide dismutase activity," Proceedings of the National Academy of Sciences of the United States of America, vol. 107, no. 34, pp. 15123-15128, 2010.

[59] Y. Zhang and N. Hogg, "S-Nitrosothiols: cellular formation and transport," Free Radical Biology and Medicine, vol. 38, no. 7, pp. 831-838, 2005.

[60] A. Zuin, M. Carmona, I. Morales-Ivorra et al., "Lifespan extension by calorie restriction relies on the Sty1 MAP kinase stress pathway," EMBO Journal, vol. 29, no. 5, pp. 981-991, 2010. 
[61] T. I. Lee, N. J. Rinaldi, F. Robert et al., "Transcriptional regulatory networks in Saccharomyces cerevisiae," Science, vol. 298, no. 5594, pp. 799-804, 2002.

[62] D. B. Berry and A. P. Gasch, "Stress-activated genomic expression changes serve a preparative role for impending stress in yeast," Molecular Biology of the Cell, vol. 19, no. 11, pp. 4580-4587, 2008.

[63] G. Chua, Q. D. Morris, R. Sopko et al., "Identifying transcription factor functions and targets by phenotypic activation," Proceedings of the National Academy of Sciences of the United States of America, vol. 103, no. 32, pp. 12045-12050, 2006.

[64] M. Rep, M. Proft, F. Remize et al., "The Saccharomyces cerevisiae Skolp transcription factor mediates HOG pathwaydependent osmotic regulation of a set of genes encoding enzymes implicated in protection from oxidative damage," Molecular Microbiology, vol. 40, no. 5, pp. 1067-1083, 2001.

[65] R. O. Poyton, P. R. Castello, K. A. Ball, D. K. Woo, and N. Pan, "Mitochondria and hypoxic signaling: a new view," Annals of the New York Academy of Sciences, vol. 1177, pp. 48-56, 2009.

[66] M. Ristow and K. Zarse, "How increased oxidative stress promotes longevity and metabolic health: the concept of mitochondrial hormesis (mitohormesis)," Experimental Gerontology, vol. 45, no. 6, pp. 410-418, 2010.

[67] S. Gao, J. Chen, S. V. Brodsky et al., "Docking of endothelial nitric oxide synthase (eNOS) to the mitochondrial outer membrane: a pentabasic amino acid sequence in the autoinhibitory domain of eNOS targets a proteinase K-cleavable peptide on the cytoplasmic face of mitochondria," Journal of Biological Chemistry, vol. 279, no. 16, pp. 15968-15974, 2004. 


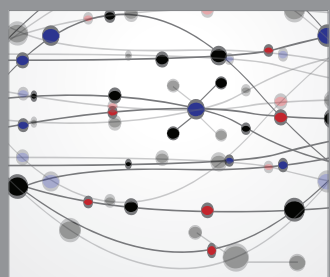

The Scientific World Journal
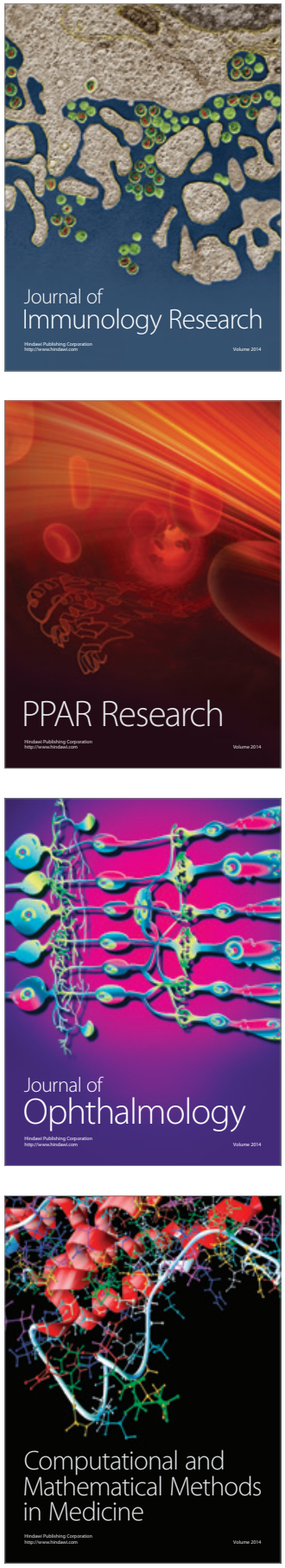

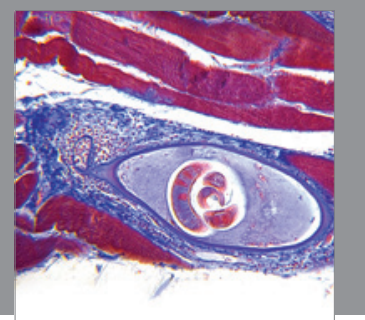

Gastroenterology

Research and Practice
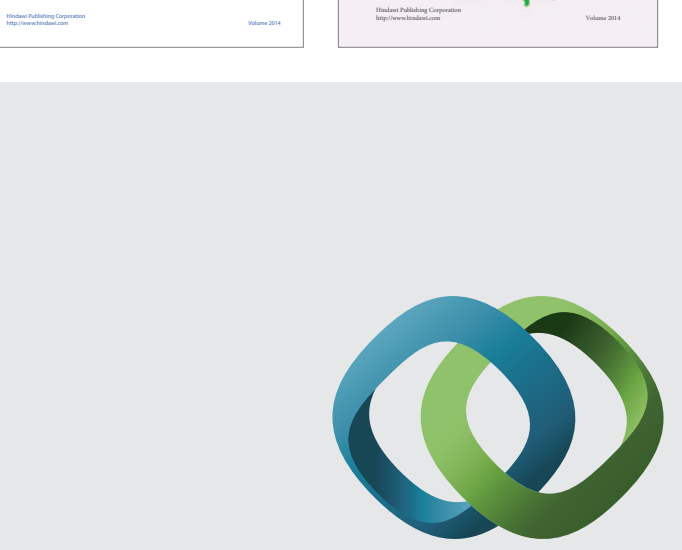

\section{Hindawi}

Submit your manuscripts at

http://www.hindawi.com
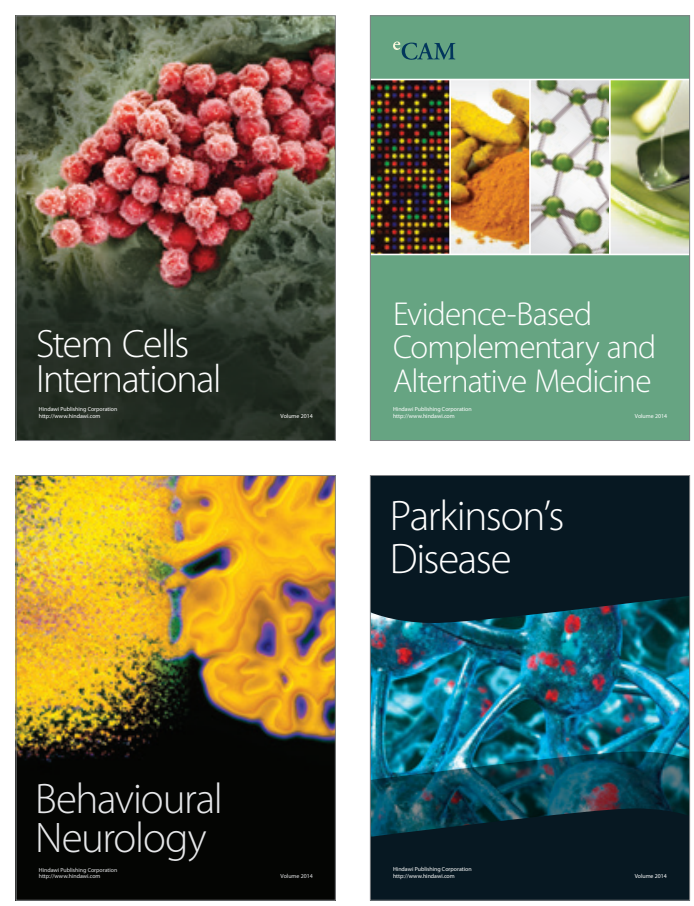

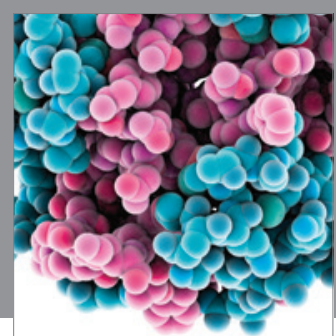

Journal of
Diabetes Research

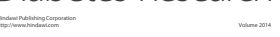

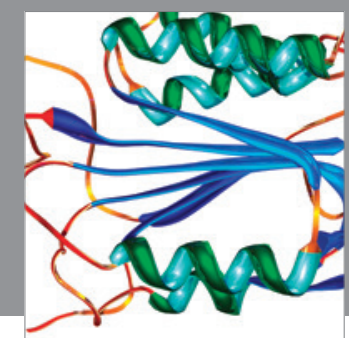

Disease Markers
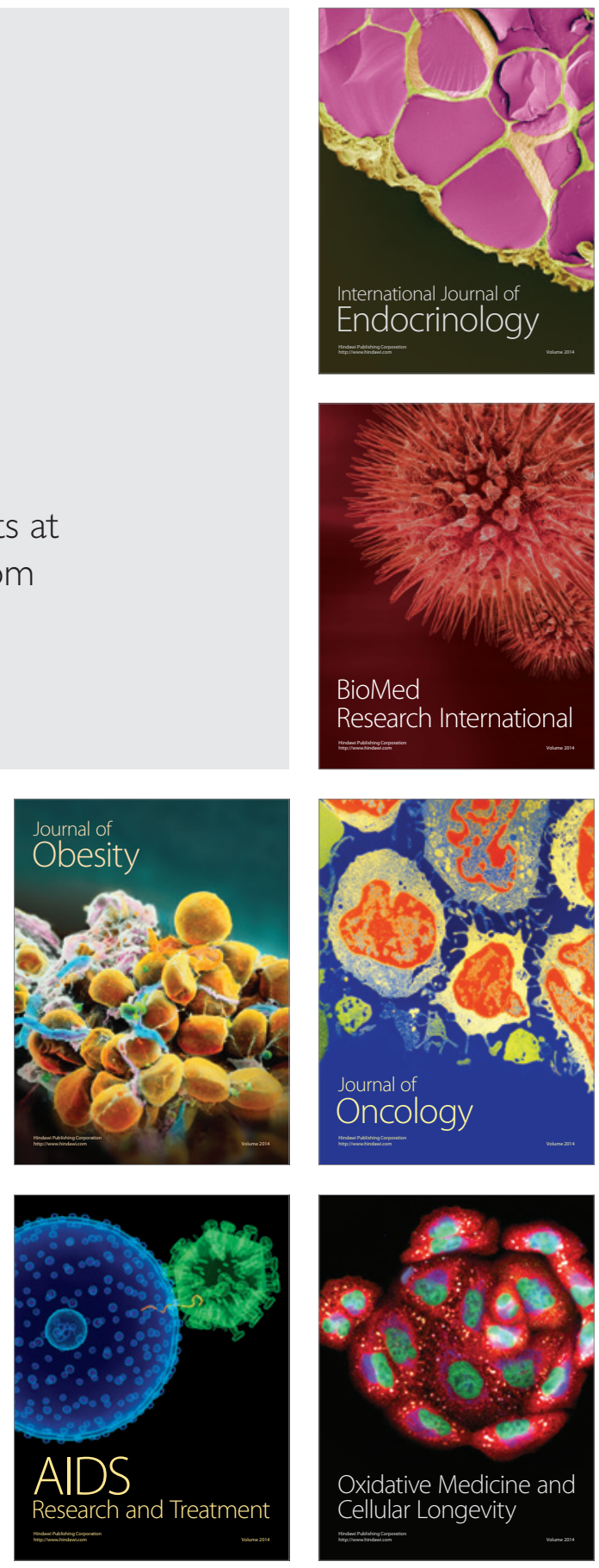